\title{
Critical Analysis of cGMP Large-Scale Expansion Process in Bioreactors of Human Induced Pluripotent Stem Cells in the Framework of Quality by Design
}

\author{
Araceli Rivera-Ordaz ${ }^{1} \cdot$ Valeria Peli $^{1} \cdot$ Paolo Manzini $^{1} \cdot$ Mario Barilani $^{1}$ (D) Lorenza Lazzari $^{1}$
}

Accepted: 6 October 2021 / Published online: 2 November 2021

(c) The Author(s) 2021

\begin{abstract}
Human induced pluripotent stem cells (hiPSCs) are manufactured as advanced therapy medicinal products for tissue replacement applications. With this aim, the feasibility of hiPSC large-scale expansion in existing bioreactor systems under current good manufacturing practices (cGMP) has been tested. Yet, these attempts have lacked a paradigm shift in culture settings and technologies tailored to hiPSCs, which jeopardizes their clinical translation. The best approach for industrial scale-up of high-quality hiPSCs is to design their manufacturing process by following quality-by-design (QbD) principles: a scientific, risk-based framework for process design based on relating product and process attributes to product quality. In this review, we analyzed the hiPSC expansion manufacturing process implementing the QbD approach in the use of bioreactors, stressing the decisive role played by the cell quantity, quality and costs, drawing key QbD concepts directly from the guidelines of the International Council for Harmonisation of Technical Requirements for Registration of Pharmaceuticals for Human Use.
\end{abstract}

\section{Introduction}

Human induced pluripotent stem cells (hiPSCs) hold great promise for revolutionizing regenerative medicine due to their potential to differentiate into any mature cell type [1]. hiPSC-based technologies have advanced to provide an unlimited source of patient-derived cells for human genetic disease modeling [2], patient-oriented drug discovery [3] and drug screening [4], and production of genetically

Mario Barilani

m.barilani@gmail.com

Araceli Rivera-Ordaz

araceli.riveraordaz@gmail.com

Valeria Peli

valeria.peli@policlinico.mi.it

Paolo Manzini

paolo.manzini58@gmail.com

Lorenza Lazzari

lorenza.lazzari@policlinico.mi.it

1 Laboratory of Regenerative Medicine-Cell Factory, Department of Transfusion Medicine and Hematology, Fondazione IRCCS Ca' Granda Ospedale Maggiore Policlinico, Via F. Sforza 35, 20122 Milan, Italy

\section{Key Points}

Human induced pluripotent stem cells (hiPSC) and their derivatives hold the potential to revolutionize the cell therapy field.

Pioneering attempts at large-scale manufacturing of hiPSC for clinical use have been exploiting existing bioreactor systems.

Relating the quality of hiPSC-based products to critical features and process parameters of existing bioreactors appears the best approach for the future development of hiPSC-tailored culture systems and manufacturing processes.

corrected [5] or healthy differentiated cell derivatives for tissue replacement clinical applications [6].

To date, several attempts have been made to advance the translation of hiPSCs as cell therapy products (CTPs) from bench to bedside in the field of regenerative medicine. hiPSC derivatives for clinical applications are classified as advanced therapy medicinal products (ATMPs), for which regulatory bodies have published guidelines, such as the 
current good manufacturing practice (cGMP) regulations. These guidelines address the novel and complex manufacturing scenarios utilized for these products and encourage a risk-based approach for their development, testing, and final implementation, entailing their translation into a cell factory production environment.

Yet, the translation from small-scale settings to largescale expansion processes needed for clinical applications has proved problematic due to several issues, including the sensitive pluripotent state of hiPSCs and their dependence on a supporting matrix [7, 8]. In the case of replacement therapies, some researchers have estimated target doses of differentiated cells per patient ranging from $10^{8}$ to $10^{10}$ cells $[9,10]$.

Over the last few years, much research has been conducted to circumvent most of the critical steps required for the large-scale production of CTPs. These efforts have mainly focused on the implementation or optimization of previous bioreactor technologies developed for other applications (e.g., vaccine production). Currently, human hematopoietic and mesenchymal stromal cells have been the major drivers of bioreactor development for CTPs [11-13]. Moreover, several studies have been conducted to test the feasibility of hiPSC expansion in existing systems (Table 1). Notwithstanding, bioreactor-based manufacturing of cellular products for clinical applications is still an immature technology, especially in relation to stability, monitoring, and quality control of the production process.

Presently, different bioreactor geometries are commercially available. Stirred tanks are the most-used bioreactors in the biopharmaceutical industry; therefore, they are the most-investigated systems for the expansion of clinical-grade hiPSCs. These bioreactors are composed of autoclavable or single-use vessels equipped with rotating blade/paddle impellers to maintain cells in suspension. Using this bioreactor geometry, an average of 2-3 $\times$ $10^{6} \mathrm{hiPSCs} / \mathrm{mL}$ are obtained in almost 7 days of culture $[14,15]$, while sequential passages can improve the final cell yield, reaching a 125- to 1100-fold maximum expansion rate $[16,17]$. Rocking bed bioreactors consist of an oscillating platform supporting culture bags. The vertical-wheel bioreactor (PBS Biotech, Camarillo, CA, USA) combines the U-shaped bottom of a single-use vessel with an innovative agitation mechanism based on a large vertical impeller, providing $2.3 \times 10^{6}$ cells $/ \mathrm{mL}$ [18]. Hollow fiber bioreactors support cell culture adherent to the inner (Quantum Cell Expansion System; Terumo, Tokyo, Japan) or outer (FiberCell Systems, New Market, MD, USA) surface of each fiber while culture medium is perfused through a disposable cartridge. Exponential growth of hiPSCs in coated hollow fibers can provide $7.99 \times 10^{8}$ cells [19]. Of note, each bioreactor architecture requires culture parameter optimization in order to maximize the cellular yield of high-quality hiPSCs.

In this framework, according to the data available at the Human Pluripotent Stem Cell Registry platform (hPSCreg: https://hpscreg.eu/browse/trials), we found 18 clinical studies using hiPSC derivatives as CTPs registered in different clinical trial registries worldwide (ClinicalTrial.gov; Japan Registry of Clinical Trials). This platform presents the upto-date status on the extent, target disease, and localization of human pluripotent stem cell (hPSC)-based clinical studies currently under way, thus providing an easily accessible reference database for hPSC-based clinical studies [20].

These clinical trials cover 14 different conditions, including macular degeneration, cardiomyocyte implantation, spinal cord injury, Parkinson's disease, retinal degeneration, etc., and contemplate the transfer of a cell product to patients.

Nevertheless, numerous other severe, untreatable, or chronic diseases, for which conventional approaches have proven to be inadequate, would benefit from these innovative hiPSC-based CTPs. The translation of these additional therapies has been impeded by the lack of significant advancements in the field of cell manufacturing aimed at facing the specific challenges of tissue replacement applications as well as the necessary paradigm shift in culture setting conditions and technologies. For the optimal design of an hiPSC bioreactor, knowledge and expertise from the actors involved at all stages, from initial development to end-user validation, should be considered. Thus, the inputs from multidisciplinary teams should be gathered to fill in many operational gaps and to assist with difficult decision-making processes.

In this context, the most appropriate approach to achieve industrial scale-up of high-quality hiPSCs is to design cell manufacturing processes according to the quality-bydesign $(\mathrm{QbD})$ principles: a scientific, risk-based framework for process design based on relating product and process attributes to product quality [21]. In this review, we focused on the hiPSC large-scale expansion via bioreactor systems, commenting on their use from the perspective of key QbD principles, and stressing the decisive role played by the cell quantity and quality. Upstream and downstream phases, including hiPSC generation by reprogramming and fill and finish steps were also briefly described and analyzed to provide the complete picture of the hiPSC manufacturing process.

\section{Quality-by-Design (QbD) Principles}

The importance of the QbD concept in pharmaceutical development has been recognized by the International Council for Harmonization of Technical Requirements for 


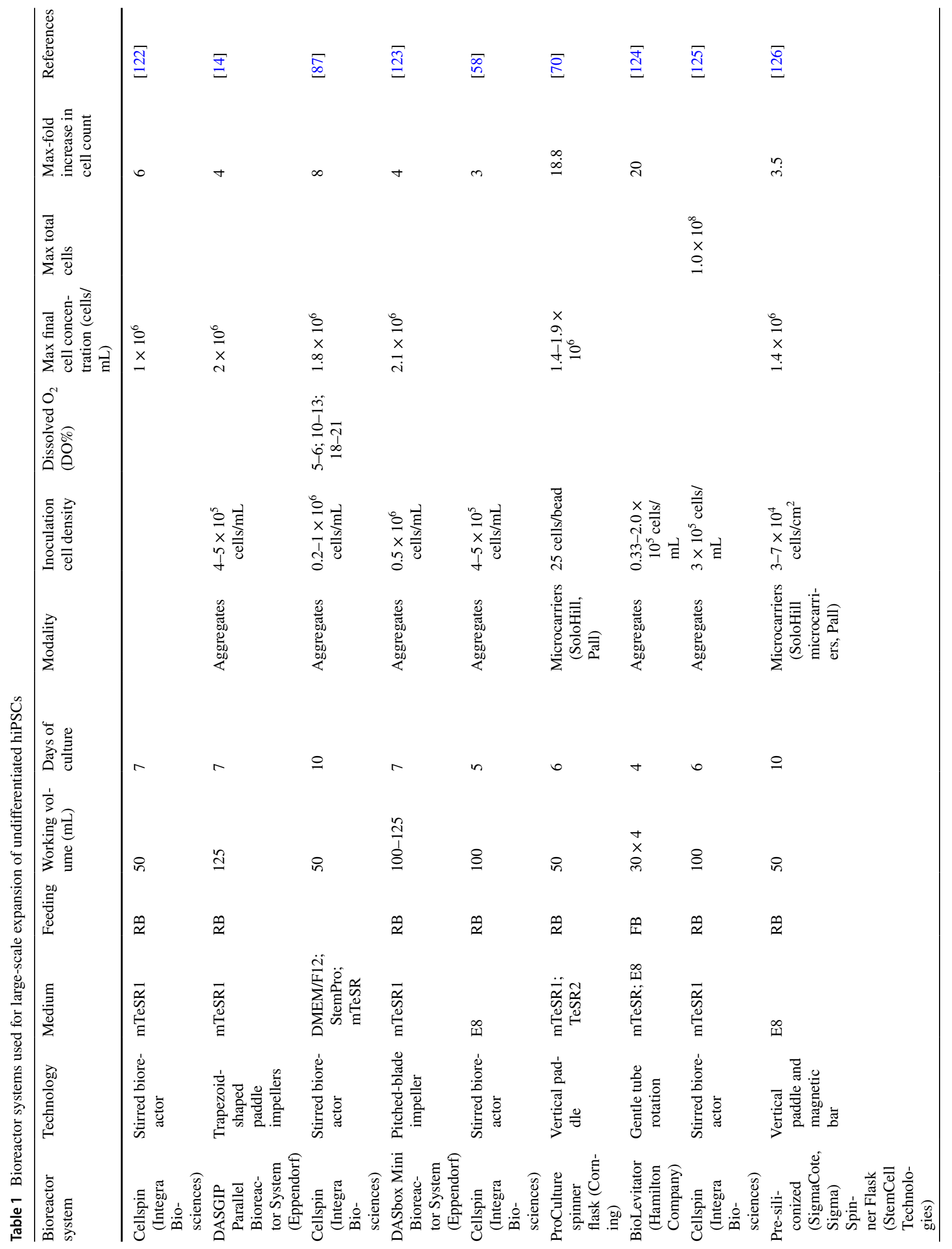




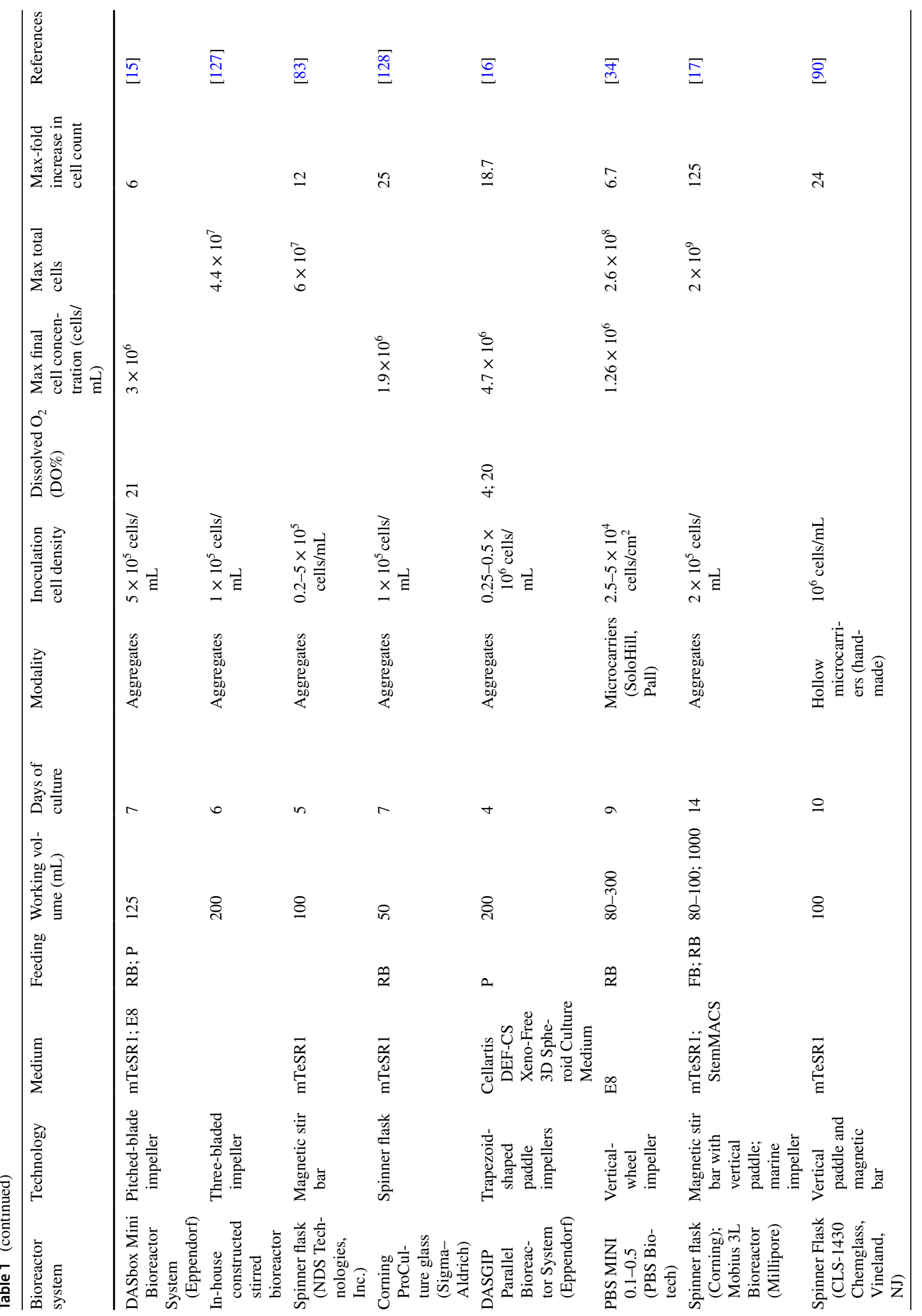




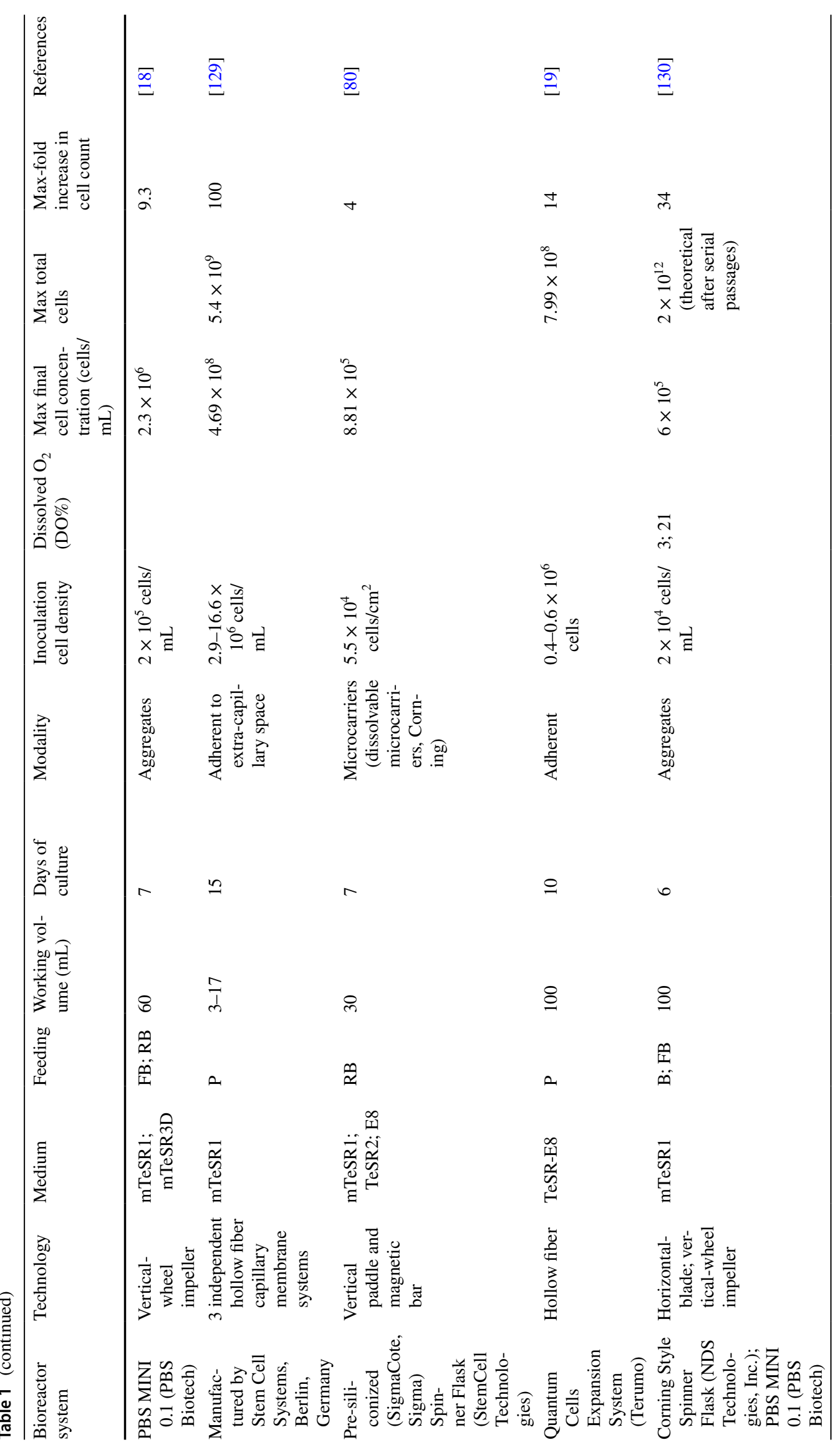




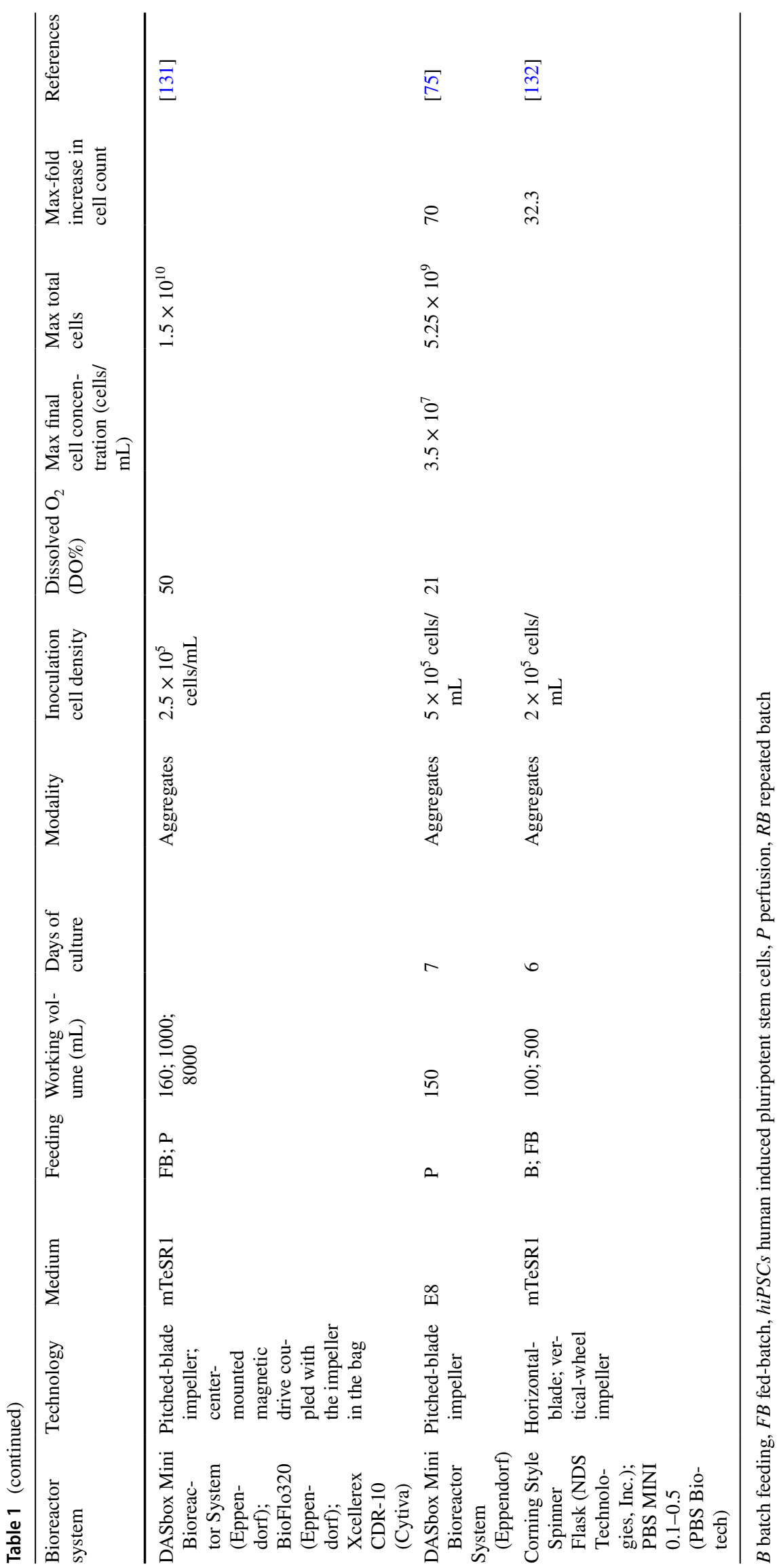

$\triangle$ Adis 
Registration of Pharmaceuticals for Human Use (ICH) in Q8(R2) (Pharmaceutical Development), Q9 (Quality Risk Management, QRM), Q10 (Pharmaceutical Quality System), and Q11 (Development and Manufacture of Drug Substance) guidelines (www.ema.europa.eu; https://www. ich.org/page/search-index-ich-guidelines). These documents provide guidance regarding the scope and definition of QbD implementation in the pharmaceutical industry. Key QbD concepts are highlighted in Table 2.

The critical aspect of a process development procedure based on an integrated QRM/QbD approach (Fig. 1) is the identification and control of the impact that the different factors can have on a possible product failure. The Quality Target Product Profile (QTPP) describes the properties of the desired end product (as it relates to quality, safety, and efficacy) and is the starting point for QbD.

The potential critical quality attributes (CQAs) can be physical, chemical, biological, or microbiological properties or characteristics that should comply with an appropriate limit, range, or distribution to ensure the desired product quality (ICH guideline Q8 (R2)). Designation of relevant critical CQAs, critical process parameters (CPPs), and critical material attributes (CMAs) involves performing experimentation, mechanistic modeling, use of prior knowledge, and application of a broad array of analytical techniques [21]. Once these parameters and attributes are identified, a risk assessment must be conducted to prioritize the study of the most influential CPPs and CMAs [22].

Summarizing the QRM actions needed to ensure and maintain a product's quality throughout its life cycle, the following steps can be followed, as outlined in ICH Q9:

- Initial risk assessment-including risk identification, analysis, and evaluation. In this step, CMAs and CPPs related to product and process design are identified, analyzed, and evaluated with regard to the impact (type, occurrence, and severity) that they may have on CQAs. QbD tools, such as Design of Experiments (DoEs), may be implemented at this stage.

- Risk control_-includes decision making for risk reduction and risk acceptance. To systematically control the risk of failure, the following QbD concepts are employed: the definition of the appropriate static or dynamic Design space (DSp) [23] to model and describe how CMAs and CPPs affect CQAs; the implementation of Process Analytical Technology (PAT) tools to monitor the manufacturing process; the setting up of the control strategy.

- Risk communication - the output/result of the QRM should be appropriately communicated and documented among all involved participants (regulators, industry, patients, etc.).

- Risk review — as a part of the ongoing quality monitoring of the product in its life cycle.

Table 2 Quality-by-design key concepts (ICH guideline Q8 (R2)) [21]

\begin{tabular}{|c|c|c|}
\hline Concept & Acronym & Description \\
\hline Quality by design & QbD & $\begin{array}{l}\text { A systematic approach to development that begins with predefined objectives and emphasizes } \\
\text { product and process understanding and process control, based on sound science and quality } \\
\text { risk management }\end{array}$ \\
\hline Quality target product profile & QTPP & $\begin{array}{l}\text { A prospective summary of the quality characteristics of a drug product that ideally will be } \\
\text { achieved to ensure the desired quality, taking into account the safety and efficacy of the drug } \\
\text { product. }\end{array}$ \\
\hline Critical quality attributes & CQAs & $\begin{array}{l}\text { Physical, chemical, biological, or microbiological properties or characteristics that should be } \\
\text { within an appropriate limit, range, or distribution to ensure product quality }\end{array}$ \\
\hline Critical process parameters & CPPs & $\begin{array}{l}\text { A process parameter whose variability has an impact on a critical quality attribute and therefore } \\
\text { should be monitored or controlled to ensure the process produces the desired quality }\end{array}$ \\
\hline Critical material attributes & CMAs & Variable elements of the input materials that influence critical quality attributes \\
\hline Design of experiments & DoE & $\begin{array}{l}\text { A structured, organized method for determination of the relationship between factors affecting a } \\
\text { process and the output of that process }\end{array}$ \\
\hline Design space & $\mathrm{DSp}$ & $\begin{array}{l}\text { The multidimensional combination and interaction of input variables (e.g., material attributes) } \\
\text { and process parameters that have been demonstrated to provide assurance of quality. A combi- } \\
\text { nation of proven acceptable ranges does not constitute a design space }\end{array}$ \\
\hline Control strategy & & $\begin{array}{l}\text { A planned set of controls, derived from current product and process understanding, that ensures } \\
\text { process performance and product quality. The controls can include parameters and attributes } \\
\text { related to drug substance and drug product materials and components, facility and equipment } \\
\text { operating conditions, in-process controls, finished product specifications, and the associated } \\
\text { methods and frequency of monitoring and control }\end{array}$ \\
\hline Process analytical technology [16] & PAT & $\begin{array}{l}\text { A system for designing, analyzing, and controlling manufacturing through timely measurements } \\
\text { (i.e., during processing) of critical quality and performance attributes of raw and in-process } \\
\text { materials and processes, with the goal of ensuring final product quality }\end{array}$ \\
\hline
\end{tabular}




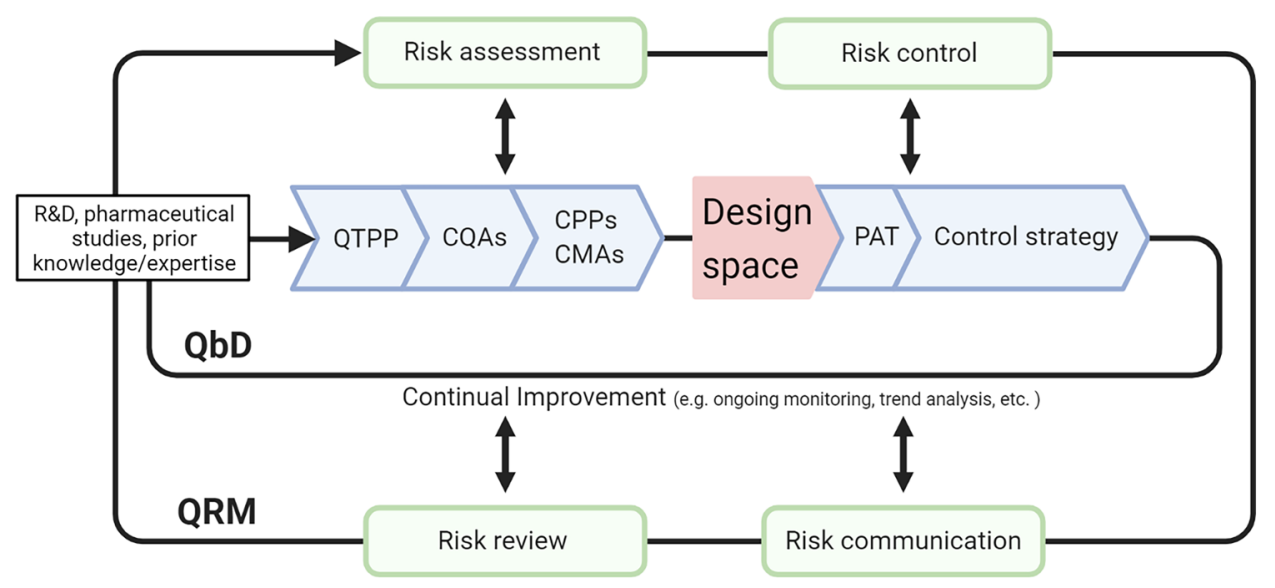

Fig. 1 The aim of pharmaceutical development is to design a quality product and manufacturing process. Information from scientific research, pharmaceutical development studies, and manufacturing experience can be the basis for an integrated QbD/QRM approach. Relevant knowledge gained from experiments giving unexpected results can also be useful. The definition of the DSp is pivotal to support and assure product quality. Changes in the product formulation and manufacturing process during development and life cycle management should be used to further support the establishment of the DSp. The DSp is proposed by the applicant and is subject to regu-

\subsection{QbD for Cell Manufacturing}

The introduction of QbD in the pharmaceutical industry was intended to promote industry's understanding of the product and of the manufacturing process, facilitating the implementation of new technologies, the process scale-up, the identification of root causes for manufacturing failures, and the reduction of production waste [24]. Implementing $\mathrm{QbD}$ to biopharmaceuticals is especially challenging due to their intrinsic complexity [24]. On that note, Maillot and co-workers reported that the completion of clinical trials using human mesenchymal stem cells (hMSCs) as therapeutic products must face many hurdles, possibly due to suboptimal quality standards early during development [25]. In this context, the wider implementation of $\mathrm{QbD}$ is pivotal in reaching industrial production for CTPs [21].

In the last decade, several studies focused on applying $\mathrm{QbD}$ to cell culture, both as an upstream process for the production of specific proteins (e.g., monoclonal antibodies) [26-33] and, more recently, for CTP manufacturing [21, 25, 34-36]. The manufacturing of CTPs for clinical application requires several of the following steps: acquisition or generation of the starting cell type; cultivation; modification; harvest; concentration; purification; formulation, and fill and finish (preparing the CTP at the correct concentration and composition, dispensing it into the final product 'container', and any post-fill processing); storage; and shipping of the product [21]. As recommended by the aforementioned ICH guidelines, CMAs and CPPs to be monitored or controlled latory assessment and approval. Working within the DSp is not considered as a change. Movement out of the DSp is considered to be a change and would normally initiate a regulatory post-approval change process (ICH guideline Q8 (R2)). $Q b D$ quality-by-design, $Q R M$ quality risk management, $Q T P P$ quality target product profile, $C Q A s$ critical quality attributes, $C P P s$ critical process parameters, $C M A s$ critical material attributes, $D S p$ design space, $D o E$ design of experiments, $P A T$ process analytical technologies, ICH International Council for Harmonization of Technical Requirements for Registration of Pharmaceuticals for Human Use. Created with BioRender.com

to ensure that the product is of the desired quality and the CQAs are met should be identified for all steps of the manufacturing process.

\subsection{Process Analytical Technology (PAT) for Cell Manufacturing}

As mentioned in Sect. 2, an essential aspect of QbD is PAT, a system for designing, analyzing, and controlling manufacturing through in-process measurements of critical quality and performance attributes with the goal of ensuring final product quality [37]. The principal factors in the widespread adoption of QbD and PAT are the scientific and financial benefits together with the regulatory support they can bring to the whole process.

PAT measurements can be in-line (the sample is measured directly in the process by in situ sensors), on-line (the sample is diverted through a bypass from the process and analyzed by a sensor, then returned to the process), at-line (the sample is collected and analyzed in proximity to the process platform), or off-line (the sample is collected and analyzed in a dedicated laboratory after handling/pretreatments) [38]. In-line and on-line solutions are preferrable over at-line and off-line ones, because they offer real time and automated measurements and analysis, avoiding possible issues arising from manual handling and time delays. However, at-line and off-line measurements may be used where no other option is available, or to validate/monitor in-line and on-line systems. 
While PAT principles have been implemented in the chemistry industry for several decades [37], their application to CTPs production is more challenging due to the difficulty of fully characterizing a living cell and obtaining relevant data in real time [36]. However, since the publication in 2004 of the FDA guidelines encouraging the use of QbD and PAT in the pharmaceutical industry (Guidance for Industry PAT, FDA 2004; https://www.fda. gov/media/71012/download) (Pharmaceutical Quality for the twenty-first century: a risk-based approach, FDA, 2014; https://www.fda.gov/about-fda/center-drug-evalu ation-and-research-cder/pharmaceutical-quality-21stcentury-risk-based-approach-progress-report), several studies have addressed PAT implementation into CTPs production [39-42].

The best approach to analyze bioprocesses' data is by several multivariate data analyses (MVDA) [36, 43], which take into account the multiple variable parameters that affect product CQAs, as well as their interaction, allowing definition of the process design space. According to Mercier and coauthors, the most powerful application of MVDA requires highly structured datasets including data from process monitoring, product quality, and process performance, which allows accurate control of product quality in real time [43].

\section{QbD for hiPSC Manufacturing}

Although the DoEs and optimization through MVDA for the improvement of hiPSC culture conditions [44-46], downstream concentration [35], and differentiation [47-49] have been described, examples of employing a QRM and QbD approach for the optimization of hiPSC expansion are limited, likely because ATMPs, such as hiPSCs and their derivatives, are a relatively new category in drug regulation. Indeed, ATMPs were included in the pharmaceutical legislation only in 2009 [50]. While several authors already focused on QbD application to cell manufacturing [21, 31, 36, 51], very few highlighted the challenges related to hiPSC large-scale expansion in bioreactors within the framework of QbD [8, 52].

\subsection{Process Mapping of hiPSC Manufacturing}

The hiPSC manufacturing process can be divided into upstream and downstream phases (Fig. 2). In general, upstream processes are those in which the biological materials are either obtained from an outside source or inoculated and grown in culture, under controlled conditions, to manufacture certain types of products, whereas downstream processes are those in which the products are harvested, tested, purified, and packaged.
For hiPSC manufacturing, the upstream phase includes generation of cell clones (reprogramming), picking/clone selection, and pre-expansion step (seed train) for inoculation of the bioreactor. The downstream phase follows large-scale hiPSC expansion with cell collection (harvest), cell concentration, and final product preparation (fill and finish). Therefore, hiPSC large-scale expansion in bioreactors, which is the main focus of the present review, is only the final step of the upstream phase. From a QbD point of view, the quality of the produced hiPSCs can be greatly influenced by the selection of raw material (upstream processing), type of culture conditions (bioprocessing), and product recovery steps (downstream processing).

In the evaluation of an hiPSC manufacturing process, it is also pivotal to underline that hiPSCs are not the final product (the CTP that will be used by the clinicians), but an intermediate product. According to the EMA guideline on manufacture of the finished dosage form [53], the definition of an intermediate product corresponds to a partly processed material that must undergo further manufacturing steps before it becomes a bulk/finished product. As hiPSCs must undergo further modifications to be used for clinical purposes, they fall within the definition of an intermediate (semi-finished) product.

On the other hand, a finished product is a medicinal product that has undergone all stages of production, including packaging, as specified by the EMA guideline on specifications and control tests on the finished product [54]. In the case of hiPSCs, this definition would be applied to the final functional differentiated cell derivatives, obtained from undifferentiated hiPSCs via further manufacturing steps, in view of tissue replacement clinical applications.

Notwithstanding the progress made in the development of devices/platforms that can be used during the different phases of hiPSC manufacturing [55], a completely standardized, closed, and automated process seems still not feasible, as it would require optimal connectivity between each device/platform developed by independent manufacturers. Moreover, full compliance to cGMP requirements would be needed.

\subsection{Quality Target Product Profile (QTPP), Critical Quality Attributes (CQAs), Critical Process Parameters (CPPs), and Critical Material Attributes (CMAs) for hiPSC Expansion}

In the case of hiPSC expansion, vast experimentation has given some insights to elucidate CPPs to understand their impact on the final product and to establish the range where it is possible to operate without affecting the CQAs [56, 57]. Table 3 lists minimal quality requirements that should 


\section{hiPSC manufacturing}

\section{Upstream}

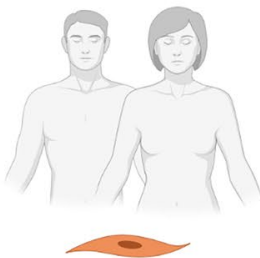

Raw material

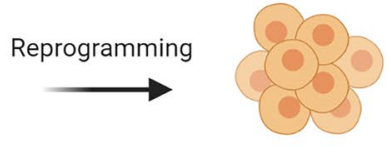

Allogeneic/Autologous/ HLA-engineered hiPSCs

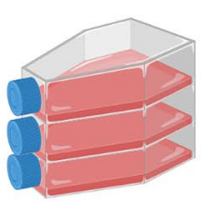

Seed train

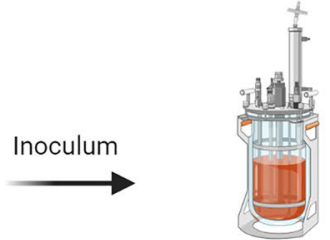

Large-scale expansion

\section{Downstream}

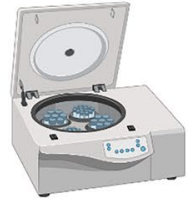

Harvest

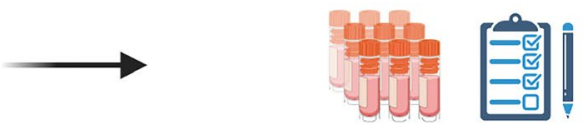

Packaging and control tests

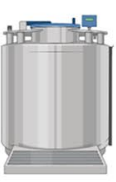

Cryopreservation of intermediate product

\section{Further bioprocessing}

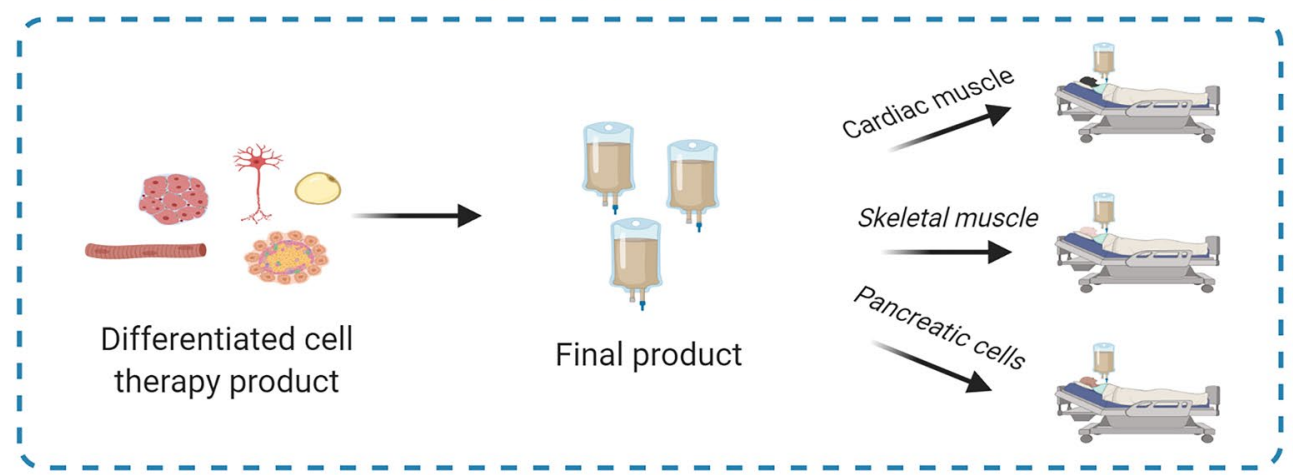

Fig. 2 The manufacturing of hiPSCs includes upstream (from collection of raw material, i.e., donors' tissue samples, to cell expansion) and downstream phases (from cell harvesting to concentration, purification, and fill and finish steps to generate a biobank of cryopreserved intermediate product, i.e., undifferentiated hiPSCs). Further bioprocessing is needed to generate functional differentiated cellular

be included in the QTPP of clinical-grade hiPSCs and their differentiated derivatives.

Presently, there is no general consensus regarding an established protocol for large-scale hiPSC expansion. The culture strategy depends on the defined QTPP because variations of a single condition can induce certain effects on the cellular product $[10,58,59]$. The initial list of potential derivatives starting from undifferentiated hiPSCs. These cell types (e.g., contractile/beating cells, insulin-producing cells) represent the final product that will be used in tissue replacement regenerative approaches. hiPSCs human induced pluripotent stem cells, HLA human leukocyte antigen. Created with BioRender.com

variable parameters can be quite extensive; however, it can be refined through experimentation to determine the significance of individual variables and potential interactions. 
Table 3 QTPP for clinical-grade hiPSCs and their differentiated products focused on minimal quality criteria required [112, 133]

\begin{tabular}{|c|c|c|c|}
\hline Attribute & Test & hiPSCs & hiPSC derivative \\
\hline Sterility & $\begin{array}{l}\text { Free of mycoplasma, other bacteria, viruses, and endotoxins, as required by } \\
\text { the cGMP guidelines }\end{array}$ & Mandatory & Mandatory \\
\hline \multirow[t]{4}{*}{ Genetic fidelity and stability } & Normal karyotype and absence of chromosomal aberrations & Mandatory & Mandatory \\
\hline & Genotyping if using an autologous hiPSC approach & Mandatory & Mandatory \\
\hline & Absence of residual reprogramming transgenes and vectors by WGES & Mandatory & Mandatory \\
\hline & $\begin{array}{l}\text { Free of tumorigenicity as analyzed by: } \\
\text { A. in vivo teratoma assay } \\
\text { B. WGES with cancer-associated gene panels } \\
\text { C. Flow cytometry with a panel of cancer-associated markers }\end{array}$ & For information & Mandatory \\
\hline \multirow[t]{3}{*}{ Identity and characterization } & Stringent assay for cell line identification by STR genotyping & Mandatory & Mandatory \\
\hline & $\begin{array}{l}\text { Expression of pluripotency-associated markers such as NANOG, OCT4A, } \\
\text { SSEA-3, SSEA-4, TRA-1-60, TRA-1-81, SOX2 }\end{array}$ & Mandatory & \\
\hline & $\begin{array}{l}\text { Absence of undifferentiated hiPSCs in the final cellular drug product and } \\
\text { expression of differentiation markers unique to the therapeutic cellular } \\
\text { product }\end{array}$ & & Mandatory \\
\hline Purity & $\begin{array}{l}\text { Absence of other contaminating lineage cell types (cell phenotype, mor- } \\
\text { phology) }\end{array}$ & Mandatory & Mandatory \\
\hline Potency & $\begin{array}{l}\text { Supporting in vivo data on cell engraftment, durability, and functional } \\
\text { improvement in preclinical models }\end{array}$ & & Mandatory \\
\hline \multirow[t]{3}{*}{ Viability } & Viability & Mandatory & Mandatory \\
\hline & Doubling time & $\begin{array}{l}\text { Not required } \\
\text { Data may be } \\
\text { added for infor- } \\
\text { mation }\end{array}$ & Mandatory \\
\hline & Cell debris & Not required & Not required \\
\hline
\end{tabular}

cGMP current good manufacturing practice, hiPSCs human induced pluripotent stem cells, QTPP quality target product profile, STR short tandem repeat, $W G E S$ whole genome and exome sequencing

\section{Critical Analysis of hiPSC Large-Scale Expansion in Bioreactors for Identification of CPPs and CMAs}

In an effort to advance the implementation of QbD in hiPSC large-scale expansion processes in bioreactors, we herein identified CPPs and CMAs potentially affecting CQAs, based on basic research data produced by our laboratory [60], our previous experience with scale-up processes [61-64], and an exhaustive review of the relevant literature. All factors that could influence the product quality were systematically compiled for a preliminary risk assessment in an Ishikawa fishbone diagram, used to visually organize these factors (Fig. 3). The same classification was used to discuss these factors in detail, as specified in the following sections.

\subsection{Equipment and Staff}

\subsubsection{Culture Platforms for hiPSC Expansion and Staff Requirements}

In standard two-dimensional culture, hiPSCs are generally plated onto matrix-covered dishes and grown as colonies, while the requirements of large-scale expansion demand a radical change of the hiPSC culture paradigm. Bioreactors allow a dramatic increase of the surface-to-volume and/or cell-to-volume ratio of the culture environment.

In this framework, the availability of guaranteed scalable systems is of particular interest for implementation of a QbD strategy. The testing of multiple cell culture conditions in parallel in a small-scale setting could be a costeffective way, with minimal operator-associated variability, for process development and optimization that could later be transferred to a large-scale setting. Systems allowing for this approach include PBS Mini bioreactors by PBS Biotech [34] and Ambr high throughput automated bioreactors (Sartorius, Göttingen, Germany) [65]. Nevertheless, further refinement could still be required when increasing the scale of bioreactors, for instance due to changes in hydrodynamics. In this respect, already established correlations, trial-and-error approaches, or in silico methods, such as computational fluid dynamics, could be implemented to select optimal culture conditions for consistent scale-up.

Another convenient feature of an optimal bioreactor system is the single-use configuration. These systems offer several advantages: simple and flexible process handling, an 


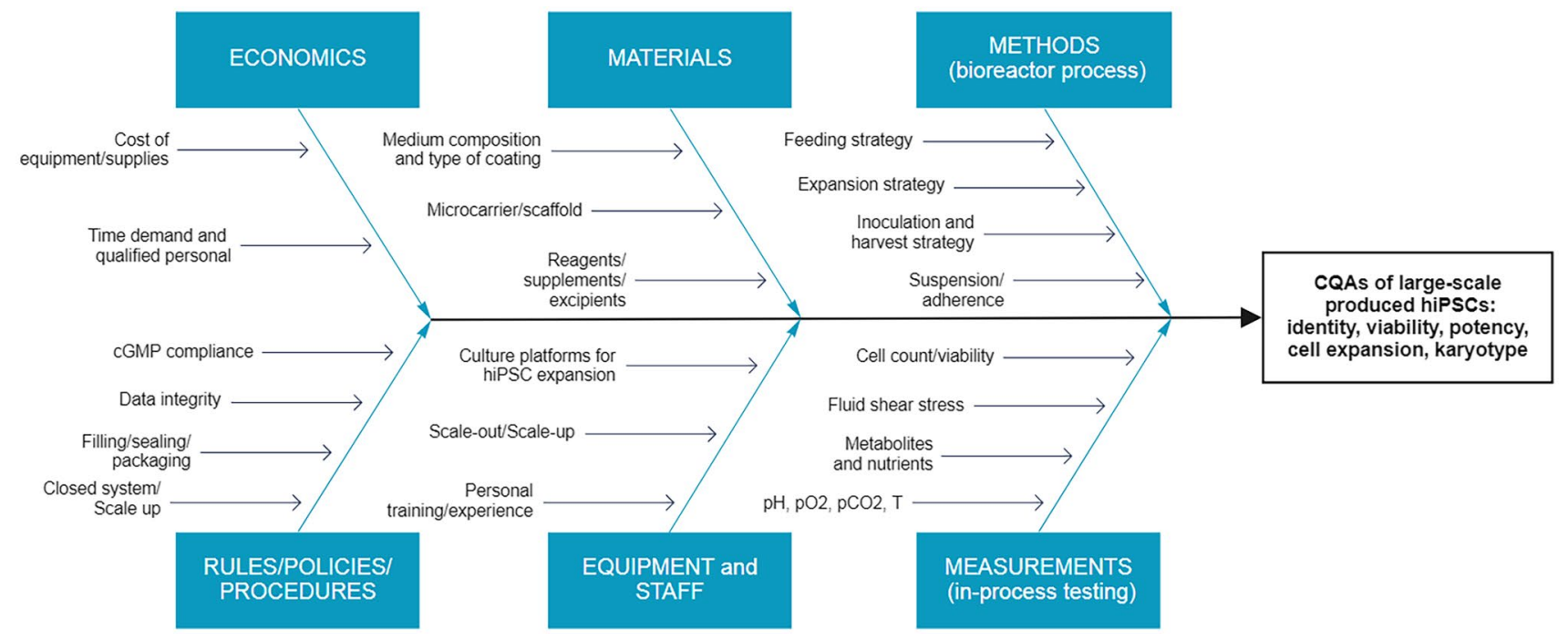

Fig. 3 Ishikawa fishbone diagram evidencing manufacturing aspects of hiPSC large-scale production processes that must be considered to identify CMAs and CPPs potentially influencing CQAs. CMAs critical material attributes, $C P P s$ critical process parameters, $C Q A s$ criti-

increase in process safety due to the reduced incidence of cross-contaminations, and no required cleaning processes. Indeed, disposable systems simplify process admission by the regulatory bodies, since the validation of cleaning and sterilization procedures is not necessary [66]. These systems could also lead to cost reductions thanks to lower cost of single-use vessels and lower personnel demand than reusable systems, even though higher running costs may arise [67]. Therefore, careful economic analysis should be performed to determine the most cost-effective strategy for each cell manufacturing process. For bioreactor evaluation, it is also important to consider the possibilities for process control (monitoring $=$ sampling) provided, as they are pivotal for the maintenance and improvement of the whole expansion process. Furthermore, the chosen system should be easily automated to limit personnel requirements.

Unfortunately, the design of the majority of commercially available bioreactors favors closed system features and automation over function/component modularity. Furthermore, manufacturers usually develop bioreactors focusing on the most common and consolidated CTPs and on a specific intended clinical application. Therefore, bioreactor users working with emerging or less used CTPs struggle to independently define in-house specific cell manufacturing protocols, let alone the application of $\mathrm{QbD}$ concepts. In the case of regenerative medicine applications, current bioreactors are mostly designed for the expansion of mesenchymal stromal cells [17]. Therefore, determining the most suitable configuration and the specific culture conditions required by hiPSCs represents one of the main challenges for the proper expansion and maintenance of these cells in such cal quality attributes, $c G M P$ current good manufacturing practices, hiPSC human induced pluripotent stem cell, $p H$ power of hydrogen, $p \mathrm{O}_{2}$ partial pressure of oxygen, $\mathrm{pCO}_{2}$ partial pressure of carbon dioxide, $T$ temperature. Created with Miro.com

bioreactors, especially when the final product needs to be cGMP compliant.

\subsubsection{Process Scale-Out and Scale-Up}

CTP doses are often undefined for many hiPSC applications, posing another level of uncertainty that would favor systems offering different scale-up options [66]. For newly generated hiPSC batches or low quantities of starting hiPSCs, an initial pre-expansion step is necessary [60]. The process of obtaining a minimum number of cells to enter scale-up can be performed via a scale-out phase. The principle of scaleout is that the culture surface area is increased without the introduction of a disruptive technology. Essentially, the size and geometry of the single hiPSC culture unit is maintained, while the number of parallel plates is increased [52]. Therefore, the scale-out approach relies on the multiplication of conventional two-dimensional vessels to increase the number of hiPSCs. In contrast, scale-up strategies rely on bioreactor systems for maximization of cell harvest by a complete reinvention of the culture strategy, optimization of scaffold/ vessel geometries, and redefinition of growth parameters.

Through scale-out, large numbers of cells can be obtained; however, it is an expensive and space-consuming configuration without process parameter monitoring [52]. Hence, scale-out is not suitable for large-scale production, but it can be adopted for the pre-expansion phase to determine the optimal number of cells for inoculation. 


\subsection{Rules and Policies}

According to the US Food and Drug Administration (FDA) and the European Medicines Agency (EMA), if the output of a bioreactor meets the definition of ATMP, cGMP requirements must be fulfilled. Therefore, the use of xenofree systems not relying on conventional feeder cells used in research settings for growth and physical support of hiPSC cultures [68] is recommended. Xeno- and feeder cell-free solutions include chemically defined media for growth, recombinant proteins or synthetic molecules for the coating of culture surfaces, and synthetic biomaterials/scaffolds for more advanced applications (e.g., differentiation, encapsulation) [69]. Following a QbD approach, a complete analysis of these components on a scalable process must be performed according to the desired final product. Thus, the expansion of hiPSCs under clinical-grade cGMP standards is a complex process whereby the characterization and demonstration of comparability among hiPSC batches, passages, and CQAs are essential and need to be well documented.

\subsection{Methods}

Establishing optimal culture conditions is necessary to obtain the desired final cell yield and phenotype. This becomes even more important with hiPSCs, since the main purpose of a suitable expansion is to maintain their undifferentiated state. Thus, before starting an hiPSC culture in a bioreactor, some considerations must be addressed.

\subsubsection{Adherence and Suspension Strategies}

Bioreactor-based culture platforms for the scale-up culture of hiPSCs offer either an adherence or matrix-free suspension strategy. While the former is represented by growth onto hollow fibers (conventional two-dimensional surfaces folded into three-dimensional structures) or onto microcarriers, the latter comprises aggregate approaches that can be combined with encapsulation technologies. Both microcarriers and hollow fibers provide surfaces for hiPSC adherence, concomitantly optimizing the area/volume ratio and making the transition from two-dimensional to large-scale expansion easier [70].

The culture of hiPSCs as three-dimensional aggregates is a completely different approach [71]. Indeed, seeding and maintaining hiPSCs in aggregates recapitulates the structure of the inner cell mass at the blastocyst stage [72]. Self-aggregation of hiPSCs due to strong cell-cell interactions and extracellular matrix secretion leads to the formation of compact cell spheres, which are independent of the anchorage to other surfaces, thus making the process more cost effective [16]. This culture strategy is the most popular for bioreactor-based hiPSC expansion
[73], mostly because of the higher viability and proliferation rate of hiPSCs and no requirement for external matrix addition [71]. Furthermore, the aggregate culture of hiPSCs is a great starting point when the final goal is their differentiation into mature specialized cell types: a direct switch from pluripotency to a specific lineage can be easily obtained by replacing the expansion medium with a differentiation one [74]. The highest yield of hiPSCs was achieved by Manstein et al., who obtained $5.24 \times 10^{9}$ hiPSCs in $150 \mathrm{~mL}$ [75].

Nevertheless, without a specific CTP-tailored QbD approach, some hurdles remain for a proper expansion of hiPSCs with this method. An important factor that must be strictly controlled is the aggregate size. It has been shown that aggregates exceeding a diameter of $\sim 300 \mu \mathrm{m}$ experience hypoxia and a low nutrient concentration in their core, resulting in cell necrosis and loss of pluripotency [16, 76-78].

The use of microcarriers can provide both physical support for matrix coating and adherent growth. Microcarriers can float inside suspension-based bioreactors at high concentrations, thanks to diameters varying from $10 \mu \mathrm{m}$ to $5 \mathrm{~mm}$ [79]. This technology allows for the establishment of precise seeding densities, which are calculated from the microcarrier dimensions and surface area. In this setting, hiPSCs attach as a monolayer to microcarriers, and every cell is exposed to nutrients and oxygen, which are crucial for the preservation of pluripotency and self-renewal. Moreover, the final cell yield can be easily adjusted by changing the amount of microcarriers.

A potential limitation of hiPSC expansion in adherent conditions is that an additional detaching step is needed to perform subsequent manufacturing operations. Thus, this method is more laborious and riskier, especially with regard to viability and sterility. For instance, the use of conventional polystyrene microcarriers has been shown to lead to a poor harvest efficiency in terms of viable hiPSCs compared with less common biodegradable microcarriers [80]. Indeed, most commercially available microcarriers are optimized for cell adhesion and growth, but not for cell detachment, due to their primary use in vaccine or protein production processes, where cell harvest is not needed [17]. Furthermore, some microcarriers are not functionalized to guarantee adherence and must be processed before use. Therefore, the microcarrier most suitable for hiPSCs and the bioreactor system must be carefully selected.

\subsubsection{Upstream Strategies: Reprogramming and Inoculation}

Reprogramming and clone picking are extremely crucial and tricky steps of hiPSC manufacturing. During this phase, hiPSCs are grown as compact colonies of adherent cells 
showing epithelial-like morphology. These operations are usually performed manually in open systems, and heavily rely on the expertise of the operator [60]. However, recent technological advancements might allow for their automation and standardization. For instance, a microfluidic-based reprogramming protocol in a closed system has recently been developed, guaranteeing highly efficient and cost-effective induction of pluripotency in human somatic cells [81]. Moreover, automated cell imaging, picking, and initial preexpansion of reprogrammed clones can be achieved through the use of specific devices, such as the CellCelector (ALS, Jena, Germany), which reduces costs, time, and operatordependent variability of these steps [82].

During the pre-expansion phase needed for the generation of an adequate number of cells for inoculation of the bioreactor, hiPSCs may be adapted to grow as three-dimensional aggregates, instead of two-dimensional colonies. Indeed, a critical choice concerns whether the hiPSCs are inoculated into the bioreactor as single cells, small clumps, or aggregates. The selection of two-dimensional or threedimensional seed train strategies should be carefully evaluated and related to the desired quality of hiPSCs and their intended clinical use (e.g., lineage-specific differentiation, master cell bank).

Furthermore, inoculation can affect cell survival and adhesion to hollow fibers and microcarriers as well as influence aggregate formation. Indeed, the inoculum cell concentration determines the number of generated hiPSC aggregates [16]. The inoculum can also affect the timeframe needed to reach the optimal aggregate size or the expected cell number. Depending on the adopted culture strategy, the inoculation parameters can be balanced to optimize the cell yield and quality [83].

\subsubsection{Expansion Strategy}

A general parameter that can be modulated during hiPSC expansion is the control of the dissolved oxygen (DO) concentration. Although hiPSCs are traditionally cultured in $20 \%$ oxygen, beneficial effects of a reduced oxygen concentration toward physiological levels $(2-6 \%)$ have been described [16, 71]. Therefore, considering the QbD point of view, real-time and precise monitoring of DO should be a feature of the bioreactor of choice for hiPSC expansion.

The expansion of hiPSCs as aggregates requires (i) control of their size and (ii) protection from shear stress, a mechanical force generated by the friction of liquids against the cell membrane. The aggregate size can be controlled in hiPSC cultures via optimization of the impeller type and agitation speeds. For example, the aggregate size is reduced with a vertical-wheel bioreactor, which guarantees efficient homogenization of the medium. Using this system, aggregates with an average diameter of $\sim 350 \mu \mathrm{m}$ are generated $\left(2.3 \times 10^{6}\right.$ cells $\left./ \mathrm{mL}\right)$, while preserving pluripotency [18].

Regarding shear stress, intense stirring of the impeller is required to maintain proper transport of nutrients and gases to larger numbers of hiPSCs expanded as aggregates in suspension bioreactors [84]. As hiPSCs are sensitive to high shear stress [85], unexpected cell death [86, 87] and uncontrolled differentiation in other PSCs $[88,89]$ may result. In 2018, a novel type of hollow microcarrier was designed. This microcarrier consists of a microsphere in which hiPSCs grow onto the inner surface, protected from shear stress, and openings on the surface allow for diffusion of gasses and nutrients [90]. Using this new technique, hiPSCs can be maintained and correctly differentiated, but further developments are needed for its translation to the GMP environment. A similar approach to protect hiPSCs from shear stress was developed by TreeFrog Therapeutics (Patent number WO2019/224467; Pessac, France). The proprietary C-Stem ${ }^{\mathrm{TM}}$ technology allows for high-throughput cell encapsulation, which generates hiPSC-containing alginate capsules that provide resistance to mechanical stress and allow nutrients and gas to enter the capsule, thanks to its permissive porousness.

Therefore, a QbD point of view would favor the careful assessment of the proper configuration of impellers to maximize medium mixing and minimize hydrodynamic shear stress.

\subsubsection{Feeding Strategy}

The way depleted medium is replaced by fresh medium can greatly affect cell expansion. When planning the culture setup, it is important to establish how much medium must be replaced and how often. Therefore, different feeding strategies can be adopted, including batch feeding, fed-batch, repeated batch, and perfusion.

If a batch feeding strategy is adopted, complete medium is provided only once when the cells are seeded. The culture medium is not replaced, and fresh medium is not added during the entire process of cell expansion. In other words, a batch bioreactor consists of a closed system in which all nutrients provided at the beginning of the culture are progressively metabolized by the cells. The increase of cell biomass is proportional/correlated to nutrient consumption and metabolite production so that the cells reach a steady state and stop proliferating. Therefore, batch feeding is not suitable for prolonged cell cultures. Nutrient reduction can be overcome with fed-batch feeding, in which limited amounts of supplements/nutrients are continuously added to the culture medium. Because no removal of depleted medium occurs, the culture volume is gradually increased. 
In the case of hiPSCs, the progressive accumulation of metabolites (fed-batch) as well as reduction of the nutrient concentration (batch) can alter the cell yield, phenotype, and behavior. For instance, slow glucose refueling and a low lactate concentration due to fed-batch feeding can lead to an hiPSC metabolic switch [18].

For repeated batch feeding, a constant volume of culture medium is systematically replaced in order to restore the nutrient and metabolite levels. This induces 'zig-zag-like patterns' in the metabolic parameters of the hiPSC culture, even though the nutrients are never completely exhausted and the lactate level does not reach the inhibitory concentration [34]. As in the repeated batch strategy, perfusion provides medium flow in and out of the bioreactor so that the culture volume does not change when fresh medium is added. For both of these strategies, hiPSCs must be retained inside the bioreactor by a retention device. Perfusion is characterized by continuous medium replacement with a constant flow rate, so that ups and downs in metabolic parameters typical of repeated batch systems are avoided. This strategy leads to optimal results in terms of hiPSC yield and aggregate size, as nicely demonstrated in suspension-based systems compared with repeated batch feeding systems [15] as well as when a higher dilution rate is adopted to avoid lactate accumulation to inhibitory concentrations [16].

\subsubsection{Downstream Strategies: Harvest, Concentration, Fill and Finish}

Downstream processing is a fundamental step in cell manufacturing, as the concentration of the product is typically high and suboptimal conditions at this stage can have a substantial effect on the final product [91]. Following expansion, cells need to be harvested, concentrated, washed to discard unwanted contaminants, formulated in a cryopreservation buffer, transferred into containers, and stored in liquid nitrogen vapor [91, 92].

With regards to the harvest strategy, hiPSCs suffer during single-cell enzymatic dissociation and endure passaging as small clumps (5-20 cells) much better by enzyme-free methods, that is, ethylenediamine tetraacetic acid (EDTA) in phosphate-buffered saline [60, 93]. However, this seeding method does not provide a precise starting cell density, which constitutes a significant parameter in a scale-up process. Furthermore, it is difficult to control the clump size, which possibly leads to undesired differentiation and increased apoptosis. Media supplementation with a smallmolecule Rho kinase inhibitor (ROCK-I, Y-27632, $10 \mu \mathrm{M}$ ) prevents dissociation-induced apoptosis, thus enhancing cell survival and viability. Yet, ROCK-I treatment must be finely controlled in terms of the exposure time, since hiPSC differentiation has been demonstrated for longer treatment periods [94].
Single-cell solutions can be obtained with different enzymatic detachment strategies. Appropriate enzyme selection is critical because hiPSCs can undergo stress and alter their viability if they are treated with aggressive enzymes. Trypsin is the most widely used enzyme for this purpose, but it can cleave cell-surface proteins and damage cell membranes [95]. Furthermore, it requires neutralization to stop enzymatic activity. TrypLE, a recombinant animal-free form of trypsin, is gentler on cells, only requires dilution to stop its activity, and is available in cGMP-grade formulations (e.g., CTS $^{\text {TM }}$ TrypLE ${ }^{\mathrm{TM}}$ Select Enzyme; Thermo Fisher Scientific, Waltham, MA, USA). Another alternative is Accutase ${ }^{\mathrm{TM}}$, a commercially available solution of proteolytic and collagenolytic enzymes, which is broadly employed in hiPSC singlecell harvest and mimics the action of both trypsin and collagenase. These enzymatic approaches can be coupled with nonenzymatic strategies. For instance, the combination of enzymatic detachment with resonance vibrations improved hiPSC recovery from stacked culture plates systems compared with classic enzymatic methods [95]. This harvest strategy was implemented for long-term cultures without altering the hiPSC karyotype, stemness, and pluripotency. The best strategy to optimize cell harvest may be to balance enzymatic/nonenzymatic methods, time of exposure, and possible combination with other approaches, depending on the desired outcome, setting, or subsequent steps.

Traditionally, cell concentration is achieved using benchtop centrifuges, while manual washing, formulation, and filling are performed under laminar air flow cabinets [91, 96]. However, as process scale-up and larger volumes are produced, this open system approach is becoming unfeasible, as operations entail a larger risk of contamination, are labor intensive, and cannot be automatically monitored [91].

Tangential flow filtration (TFF) and continuous counterflow centrifugation allow for simultaneous washing and volume reduction steps in a closed system [36, 91, 92]. In TFF, cells are recirculated along membranes, while fluid pressure removes the spent media through filtration. Shear rate and pressure are important TFF CPPs that can affect the quality of recovered cells [36]. UniFlux (GE Healthcare, Chicago, IL, USA) and KrosFlo (Repligen, Waltham, MA, USA) are closed, fully automated TFF integrated systems that allow for the processing of large volumes, respectively up to $10,000 \mathrm{~L}$ and $5000 \mathrm{~L}$. In counterflow centrifugation, cells flow in the opposite direction to the centrifugal force [91]. KSep System (Sartorius) is a fully automated and continuous counterflow centrifugation system that is capable of processing batches of up to $6000 \mathrm{~L}$ of feed material. Recently, Cunha and co-workers optimized TFF for the concentration of hiPSCs and identified the shear rate ranges that maximize cell recovery yield and viability at different medium cell loads [35]. 
Acoustic filtration is a novel technique that makes use of acoustic waves to selectively retain, wash and concentrate cells without negatively affecting them [97, 98]. In 2014, FloDesign Sonics (Millipore Sigma, Burlington, MA, USA) patented Ekko, a closed scalable system to perform acoustic filtration (Patent number USOO8889388B). This platform is promising for hiPSCs, as low shear stress allows for minimal impact on cell viability.

Formulation consists of the addition of additives, typically dimethyl sulfoxide (DMSO), to cell containers to achieve the desired concentration of all the final product components and to allow cryopreservation [36]. Cooling rate has been shown to influence survival after thawing in a cell type-dependent fashion and, therefore, is a CPP that would need careful characterization for hiPSCs and their differentiated derivatives [99].

The implementation of closed controlled systems to downstream processing potentially allows for harvesting and cryopreservation of cells during the same day, increasing final viability and reducing the risk of contamination, especially in view of the growing lot sizes, driven by the advances in cell expansion technologies [91]. Automated inventory management will also be increasingly important, as transient removal of frames or racks from storage is a significant cause of cryopreserved cell viability reduction $[91,99]$.

\subsection{Materials}

\subsubsection{Media}

Significant efforts have been made to develop cell- and xenofree hiPSC culture systems [100]. These media and matrices evolved from more complex formulations containing undefined supplements of animal origin [101] to simpler ones, partly or completely chemically-defined, containing humanderived supplements [102] or solely recombinant proteins [103]. This was achieved by considering the signaling pathways that help sustain pluripotency in hiPSCs and dissecting positive and negative contributions of single medium and matrix components to define the core components needed for hiPSC growth and pluripotency maintenance [8]. Despite their less complex composition, low-protein media (e.g., Essential $8^{\mathrm{TM}}$ and TeSR ${ }^{\mathrm{TM}}-\mathrm{E} 8^{\mathrm{TM}}$ ) have shown promising results in studies addressing maintenance of proliferation and differentiation properties while preserving genomic stability [104].

Yet, formulations of commercially available media remain largely undisclosed, even though reference to the original published compositions is sometimes stated by the manufacturer. This poses potential limitations to the smooth translation of these media to clinical applications, when risk assessment must be performed for quality assurance of the
hiPSC manufacturing process. For the recently available cGMP-compliant products (e.g., CTS ${ }^{\mathrm{TM}}$ Essential 8 ${ }^{\mathrm{TM}}$, iPSBrew GMP Medium), the manufacturers provide specific documentation to meet international and national requirements for the approval of hiPSC manufacturing processes by the regulatory bodies. Many of these media support hiPSC expansion in a diverse range of bioreactors (Table 4).

Medium supplements may be employed to ameliorate hiPSC harvest and quality in specific manufacturing settings. For instance, in suspension hiPSC culture approaches, dextran sulphate exerts antiapoptotic effects and reduces cell aggregation, allowing higher control of aggregate size [105], an increased hiPSC final yield, and faster growth kinetics compared with basal complete medium in a single-use vertical-wheel bioreactor [18].

From a QbD perspective, the choice of medium apparently does not pose any difficulties, considering the success of hiPSC growth and expansion. A different result may arise from the subsequent analysis of hiPSC quality in terms of differentiation toward restricted lineages or mature cell types.

\subsubsection{Microcarriers and Coatings}

Microcarriers are designed with different materials, sizes, and shapes, which significantly affect the expansion and differentiation ability of cultured cells, especially if the main target is a large-scale hPSC culture [106]. Commercially available beads are made with several materials, such as glass, silica, and cellulose; but plastic (e.g., polystyrene) and dextran-based microcarriers are actually the most widely employed for this kind of culture [79]. For instance, polystyrene beads like SoloHill ${ }^{\circledR}$ Microcarriers (Sartorius) and Cytodex 1 and 3 (GE Healthcare) provide precise specifications (e.g., absence of animal products) and quality control tests, which make them the favorite choice for hiPSC expansion in cGMP conditions.

Microcarrier sizes can be very different, but a $100-250 \mu \mathrm{m}$ diameter range is generally preferred. Smaller microcarriers can be employed in higher quantities inside a single bioreactor, leading to a higher growth surface area compared with larger microcarriers. However, larger microcarriers (i.e., Cytodex 1 and 3) can achieve a higher hPSC proliferation compared with smaller microcarriers due to less microcarrier aggregation, which decreases the available surface [106]. Microcarriers are generally compact and round shaped, but other configurations like micro- and macro-porous microcarriers have been developed to harbor cells inside a niche, protecting them from shear stress. However, they yield lower hPSC quantities than compact microcarriers [106].

Importantly, cell attachment can be improved by an additional surface coating. Indeed, most microcarriers are functionalized with positively charged groups, such as 
Table 4 Examples of commercially available culture media for hiPSC expansion used in bioreactor settings

\begin{tabular}{|c|c|c|c|}
\hline Medium & Producer & Tested in bioreactor & References \\
\hline $\mathrm{mTeSR}^{\mathrm{TM}} 1$ & $\begin{array}{l}\text { Stemcell Technologies (Vancouver, } \\
\text { Canada) }\end{array}$ & $\begin{array}{l}\text { Vertical-wheel impeller; hollow fiber; } \\
\text { vertical paddle; rotating blade impeller; } \\
\text { spinner flask }\end{array}$ & {$[15,17,18,80,90,129]$} \\
\hline $\mathrm{TeSR}^{\mathrm{TM}} 2$ & $\begin{array}{l}\text { Stemcell Technologies (Vancouver, } \\
\text { Canada) }\end{array}$ & Spinner flask; vertical paddle & {$[70,80]$} \\
\hline $\mathrm{TeSR}^{\mathrm{TM}}-\mathrm{E} 8^{\mathrm{TM}}$ & $\begin{array}{l}\text { Stemcell Technologies (Vancouver, } \\
\text { Canada) }\end{array}$ & Hollow fiber bioreactor & [19] \\
\hline mTeSR ${ }^{\mathrm{TM}} 3 \mathrm{D}$ & $\begin{array}{l}\text { Stemcell Technologies (Vancouver, } \\
\text { Canada) }\end{array}$ & Vertical-wheel impeller & [18] \\
\hline Essential $8^{\mathrm{TM}}$ & $\begin{array}{l}\text { Thermo Fisher Scientific (Waltham, MA, } \\
\text { USA) }\end{array}$ & $\begin{array}{l}\text { Vertical-wheel impeller; rotating blade } \\
\text { impeller; spinner flask }\end{array}$ & {$[15,34,126]$} \\
\hline StemMACS iPS-Brew XF & Miltenyi (Bergisch Gladbach, Germany) & Spinner flask; rotating blade impeller & {$[17,134]$} \\
\hline StemPro ${ }^{\mathrm{TM}}$ & $\begin{array}{l}\text { Thermo Fisher Scientific (Waltham, MA, } \\
\text { USA) }\end{array}$ & Spinner flask & {$[135]$} \\
\hline $\begin{array}{l}\text { Cellartis DEF-CS Xeno- } \\
\text { Free 3D Spheroid Culture } \\
\text { Medium }\end{array}$ & $\begin{array}{l}\text { Takara Bio Europe AB (Göteborg, Swe- } \\
\text { den) }\end{array}$ & Spinner flask & [16] \\
\hline
\end{tabular}

hiPSCs human induced pluripotent stem cells

diethylaminoethyl groups (Cytodex 1), or with biological molecules, such as collagen (Cytodex 3). Matrigel also has been used for hPSC expansion on microcarriers with favorable results, but its composition limits its application in cGMP-compliant processes [107, 108]. Coating microcarriers with extracellular matrix glycoproteins can be considered as a valid alternative. Nevertheless, some of these proteins are obtained from animal sources and may suffer batch-tobatch variation, compromising their use in cGMP environments. A xeno-free solution for microcarriers as well as a hollow fiber coating with extracellular matrix recombinant proteins are considered safer technologies. More cost-effective synthetic substrates like Synthemax (Corning, Corning, NY, USA) and poly-L-lysine also have been investigated as valuable options for xeno-free hiPSC culture [70, 109].

Proper microcarriers should exhibit adequate physical and mechanical properties for a dynamic system and promote efficient hiPSC adhesion, together with a technically simple cell harvesting method [110]. Recently, novel dissolvable microcarriers for the scalable, xeno-free expansion of hiPSCs in spinner flasks have been developed [80]. These beads, developed by Corning, are made of polygalacturonic acid polymer chains coated with Synthemax II, which can be dissolved in EDTA/pectinase. This system leads to higher cell yields than conventional separation methods, without affecting the expression of pluripotency markers or the differentiation potential, which makes it a promising platform for the scalable and cGMP-compliant large-scale production of hiPSCs.

Under the guidance of QbD tools and careful evaluation of the advantages and disadvantages related to the hiPSC application, the choice of microcarrier and coating type should match the characteristics of the bioreactor used for hiPSC expansion.

\subsection{Measurements}

Real-time and in-process analytics play an important role in ensuring the final product quality and in-process corrections [111]. For example, parameters like cell metabolism should be monitored by measuring glucose consumption, lactate accumulation, and $\mathrm{pH}$ and $\mathrm{DO}$ changes in any culture medium [58]. Indeed, hiPSC differentiation into cardiomyocytes can be greatly improved by combining the effects of hypoxia $\left(4 \% \mathrm{O}_{2}\right.$ tension) with bioreactor hydrodynamics (an intermittent agitation profile) [59]; therefore, DO level and hydrodynamics profile could be CPPs that should be monitored also in other applications to ensure that hiPSC CQAs are maintained during manufacturing.

As mentioned in Sects. 4.3.1 and 4.3.3, reproducible and steady formation of aggregates of hiPSCs cultured in suspension is critical for process scalability. Certain optical techniques show potential as monitoring tools for cell health and undifferentiated status in real-time. For example, autofluorescence measurement of nicotinamide adenine dinucleotide phosphate (NADPH) and flavin adenine dinucleotide (FAD) via two-photon excitation fluorescence microscopy is an effective technique for monitoring hiPSC self-renewal stability in three-dimensional tissue constructs [8]. Raman spectroscopy and near infrared reflectance are also useful online probes for monitoring metabolites (glucose, lactate, etc.); therefore, they could provide useful information when developing chemometric models and machine-learning 
algorithms that can predict and regulate hiPSC pluripotency in real-time [111].

Measurement of these parameters is becoming more available in bioreactor systems; however, they often increase the cost for the whole production process. Automated sensors would be advantageous for real-time bioreactor process monitoring; unfortunately, they are uncommon among the commercially available bioreactors.

\subsection{Economics}

From an economic point of view, the most practical approach for hiPSC-based cell therapy is the allogeneic strategy rather than the use of autologous hiPSCs. Indeed, it is likely to cost approximately US $\$ 800,000$ to produce a clinical grade autologous hiPSC-derived cellular product in compliance with cGMP requirements [112]. Furthermore, autologous hiPSC production should be performed in fully automated closed bioreactor systems to minimize cross-contamination between autologous cells from different patients, providing the cells for one patient in one vessel.

The current financial costs of personalized hiPSC production are unaffordable for most patients; therefore, the generation of allogeneic human leukocyte antigen (HLA)homozygous hiPSC banks would be beneficial. To this aim, the Global Alliance for hiPSC Therapies was formed to support the creation and global harmonization of hiPSC banking for clinical applications [8]. Nevertheless, it is still difficult to recruit healthy universal (type O-negative) blood donors to match any existing HLA allelic combination, especially for countries with high genetic variability. Interestingly, strategies to enable allogeneic hiPSC-derived therapies to evade immune responses have been proposed [113, 114].

The allogeneic approach can reduce the cost of hiPSCbased cell therapy compared with the autologous approach and would facilitate authorization processes by regulatory bodies [112]. Thus, a patient could effectively benefit from an off-the-shelf product more readily, especially for critical subacute conditions such as myocardial infarction and spinal cord injury. Another advantage of the allogeneic approach is that $\mathrm{QbD}$ would be performed as a unique and definitive process that is not vertically focused on single patients but horizontally focused on hiPSC quality related to the final clinical application after expansion.

\section{Further Improvements}

With the development of automation, closed bioreactor cell culture systems, and validated testing protocols, the objective to industrialize hiPSC manufacturing is now closer than ever. However, currently the following cell therapy clinical trials based on the use of bioreactors are listed in the ClinicalTrials.gov database: culture of hMSCs for Laryngo-Tracheal Tissue-Engineered Clinical Transplantation (NCT01997437); safety of Intramuscular Injection of Allogeneic PLX-PAD Cells for the Treatment of Critical Limb Ischemia (NCT00919958); a phase I/II immunotherapy with NK cells expanded in bioreactor for mild infected COVID-19 patients, which was withdrawn (NCT04344548). No search result indicated the use of bioreactor-expanded hiPSCs in current clinical trials. Specific research concerning large-scale hiPSC expansion strategies urgently needs to be intensified because the reliability of hiPSC manufacturing is significantly involved in the success of cell therapies based on differentiated derivatives used as ATMPs. Without an effective manufacturing strategy, cell therapy cannot be successful.

The application of the QbD strategy presented herein to hiPSC-based ATMPs would greatly improve process and product understanding and outcomes. Indeed, the biological complexity of CTPs makes the iterative philosophy of $\mathrm{QbD}$ especially relevant to this therapeutic modality and critical to the success of the CTP industry [21]. As mentioned by Donald Norman in his book The Design of Everyday Things, it is the goal of the designer to reduce the probability of error, using affordance, constraints, and good mapping for operator guiding. Even for well-designed bioreactors, operatorfriendly features and engineering solutions are missing. For example, depending on the bioreactor, the need to fill singleuse plastic bags with large quantities of media or reagents requires highly time-consuming manual procedures; continuous and repetitive displacement of the bioreactor itself or of its core units from the incubator to the hood is needed; and there is a lack of crucial sensors to monitor cell growth or guarantee atmospheric control. In other cases, the existing systems need many modifications to their initial configurations, which require increased costs and time to standardize manufacturing.

For the optimal design of a hiPSC bioreactor, knowledge and expertise from those involved from initial development to end-user validation should be considered. Inputs from designers, engineers, scientists, and operators should be gathered to fill in many operational gaps and to assist with difficult decision-making processes.

\section{Final Remarks and Outlook}

A QbD approach applied to CTP manufacturing processes entails that specific bioreactors and/or culture protocols must be developed and tailored for each different CTP. For instance, for hiPSCs, the differentiation phase must be evaluated separately from the expansion process. From this perspective, emerging alternatives to cell-based therapies, such as extracellular vesicles (EVs), should be considered. EVs 
refer to a heterogeneous group of cell membrane-enclosed cytoplasm-containing bodies secreted into the extracellular space by many cell types [115]. EVs are involved in many of the therapeutic effects previously ascribed to cells [116], particularly mesenchymal stem cells [117]. Furthermore, the large-scale production of EVs would require the use of bioreactor systems developed following QbD [118-120]. In this framework, the quality of both the source cells and secreted EVs should be considered [121]. Therefore, setting up a consistent manufacturing processes allowing for concomitant large-scale cell culture and harvesting of EVs could be the next big challenge for all stakeholders in the field of ATMPs.

\section{Declarations}

Funding Financial support was by PLAGENCELL, project coordinated by ASST Papa Giovanni XXIII (Fondazione Regionale per la Ricerca Biomedica, Regione Lombardia, Project nr. CP2_10/2018).

Conflicts of interest The authors declare no conflict of interest.

Ethics approval Not applicable.

Availability of data and material Not applicable.

Consent to participate/publish Not applicable.

Code availability Not applicable.

Author contributions Conceptualization was by ARO, VP, PM and MB. Literature search and analysis was by ARO, VP and PM. Formal analysis was by ARO. Funding acquisition was by LL. Project administration was by MB. Resources was by ARO. Supervision was by MB and LL. Visualization was by ARO, VP, PM and MB. Writing-original draft preparation was by ARO, VP, PM and MB. Writing-review and editing was by ARO, VP, PM, MB and LL.

Open Access This article is licensed under a Creative Commons Attribution-NonCommercial 4.0 International License, which permits any non-commercial use, sharing, adaptation, distribution and reproduction in any medium or format, as long as you give appropriate credit to the original author(s) and the source, provide a link to the Creative Commons licence, and indicate if changes were made. The images or other third party material in this article are included in the article's Creative Commons licence, unless indicated otherwise in a credit line to the material. If material is not included in the article's Creative Commons licence and your intended use is not permitted by statutory regulation or exceeds the permitted use, you will need to obtain permission directly from the copyright holder. To view a copy of this licence, visit http://creativecommons.org/licenses/by-nc/4.0/.

\section{References}

1. Takahashi $\mathrm{K}$, et al. Induction of pluripotent stem cells from fibroblast cultures. Nat Protoc. 2007;2(12):3081-9.

2. Karagiannis $P$, et al. Induced Pluripotent stem cells and their use in human models of disease and development. Physiol Rev. 2019;99(1):79-114.
3. Rowe RG, Daley GQ. Induced pluripotent stem cells in disease modelling and drug discovery. Nat Rev Genet. 2019;20(7):377-88.

4. Elitt MS, Barbar L, Tesar PJ. Drug screening for human genetic diseases using iPSC models. Hum Mol Genet. 2018;27(R2):R89-98.

5. Raya A, et al. A protocol describing the genetic correction of somatic human cells and subsequent generation of iPS cells. Nat Protoc. 2010;5(4):647-60.

6. Mora C, et al. Clinical potentials of human pluripotent stem cells. Cell Biol Toxicol. 2017;33(4):351-60.

7. Ashok P, et al. Aggregate and microcarrier cultures of human pluripotent stem cells in stirred-suspension systems. In: Turksen K, editor., et al., Bioreactors in stem cell biology. New York: Springer; 2015. p. 35-52.

8. Polanco A, Kuang B, Yoon S. Bioprocess technologies that preserve the quality of iPSCs. Trends Biotechnol. 2020;38(10):1128-40.

9. Prowse $A B$, et al. Transforming the promise of pluripotent stem cell-derived cardiomyocytes to a therapy: challenges and solutions for clinical trials. Can J Cardiol. 2014;30(11):1335-49.

10. Millman JR, Pagliuca FW. Autologous pluripotent stem cellderived $\beta$-like cells for diabetes cellular therapy. Diabetes. 2017;66(5):1111-20.

11. Eaker $\mathrm{S}$, et al. Bioreactors for cell therapies: current status and future advances. Cytotherapy. 2017;19(1):9-18.

12. Jossen $\mathrm{V}$, et al. Manufacturing human mesenchymal stem cells at clinical scale: process and regulatory challenges. Appl Microbiol Biotechnol. 2018;102(9):3981-94.

13. Stephenson M, Grayson W. Recent advances in bioreactors for cell-based therapies. F1000Research. 2018;7:517.

14. Olmer R, et al. Suspension culture of human pluripotent stem cells in controlled, stirred bioreactors. Tissue Eng Part C Methods. 2012;18(10):772-84.

15. Kropp C, et al. Impact of feeding strategies on the scalable expansion of human pluripotent stem cells in single-use stirred tank bioreactors. Stem Cells Transl Med. 2016;5(10):1289-301.

16. Abecasis B, et al. Expansion of 3D human induced pluripotent stem cell aggregates in bioreactors: bioprocess intensification and scaling-up approaches. J Biotechnol. 2017;246:81-93.

17. Kwok CK, et al. Scalable stirred suspension culture for the generation of billions of human induced pluripotent stem cells using single-use bioreactors. J Tissue Eng Regen Med. 2018;12(2):e1076-87.

18. Nogueira DES, et al. Strategies for the expansion of human induced pluripotent stem cells as aggregates in single-use Vertical-Wheel ${ }^{\mathrm{TM}}$ bioreactors. J Biol Eng. 2019;13:74.

19. Paccola Mesquita FC, et al. Laminin as a potent substrate for large-scale expansion of human induced pluripotent stem cells in a closed cell expansion system. Stem Cells Int. 2019;2019:9704945.

20. Kobold S, et al. A manually curated database on clinical studies involving cell products derived from human pluripotent stem cells. Stem Cell Rep. 2020;15(2):546-55.

21. Lipsitz YY, Timmins NE, Zandstra PW. Quality cell therapy manufacturing by design. Nat Biotechnol. 2016;34(4):393-400.

22. Nakas A, et al. Quality risk management and quality by design for the development of diclofenac sodium intra-articular gelatin microspheres. AAPS PharmSciTech. 2020;21(4):127.

23. von Stosch M, et al. Working within the design space: do our static process characterization methods suffice? Pharmaceutics. 2020;12(6):562.

24. Rathore AS, Winkle H. Quality by design for biopharmaceuticals. Nat Biotechnol. 2009;27(1):26-34. 
25. Maillot C, et al. Quality by design to define critical process parameters for mesenchymal stem cell expansion. Biotechnol Adv. 2021;50:107765.

26. Kim YJ, et al. Quality by Design characterization of the perfusion culture process for recombinant FVIII. Biologicals. 2019;59:37-46.

27. Puskeiler R, et al. The way to a design space for an animal cell culture process according to Quality by Design (QbD). BMC Proc. 2011;5(Suppl 8):P12.

28. Abu-Absi SF, et al. Defining process design space for monoclonal antibody cell culture. Biotechnol Bioeng. 2010;106(6):894-905.

29. Rouiller Y, et al. Application of Quality by Design to the characterization of the cell culture process of an Fc-Fusion protein. Eur J Pharm Biopharm. 2012;81(2):426-37.

30. Nagashima $H$, et al. Application of a quality by design approach to the cell culture process of monoclonal antibody production, resulting in the establishment of a design space. J Pharm Sci. 2013;102(12):4274-83.

31. Marasco DM, et al. Development and characterization of a cell culture manufacturing process using quality by design $(\mathrm{QbD})$ principles. Adv Biochem Eng Biotechnol. 2014;139:93-121.

32. Torkashvand F, Vaziri B. Main quality attributes of monoclonal antibodies and effect of cell culture components. Iran Biomed J. 2017;21(3):131-41.

33. Aksu B, et al. QbD implementation in biotechnological product development studies. Special topics in drug discovery. London: InTech; 2016

34. Rodrigues CA, et al. Scalable culture of human induced pluripotent cells on microcarriers under xeno-free conditions using single-use vertical-wheel ${ }^{\mathrm{TM}}$ bioreactors. J Chem Technol Biotechnol. 2018;93(12):3597-606.

35. Cunha B, et al. Finding the design space of a filtration-based operation for the concentration of human pluripotent stem cells. J Membr Sci. 2017;542:399-407.

36. Campbell A, et al. Concise review: process development considerations for cell therapy. Stem Cells Transl Med. 2015;4(10):1155-63.

37. Rathore AS, Bhambure R, Ghare V. Process analytical technology (PAT) for biopharmaceutical products. Anal Bioanal Chem. 2010;398(1):137-54.

38. Hamilton. Biopharma PAT Quality Attributes, Critical Process Parameters \& Key Performance Indicators at the Bioreactor. White Paper, 2018. https://craft-sensors.s3.amazonaws.com/ WhitePaper_Biopharm_PAT.pdf . Accessed 27 Oct 2021.

39. Carrondo MJ, et al. How can measurement, monitoring, modeling and control advance cell culture in industrial biotechnology? Biotechnol J. 2012;7(12):1522-9.

40. Streefland M, et al. Process analytical technology (PAT) tools for the cultivation step in biopharmaceutical production. Eng Life Sci. 2013;13(3):212-23.

41. Teixeira AP, et al. Advances in on-line monitoring and control of mammalian cell cultures: supporting the PAT initiative. Biotechnol Adv. 2009;27(6):726-32.

42. Chilmonczyk MA, et al. Localized sampling enables monitoring of cell state via inline electrospray ionization mass spectrometry. Biotechnol J. 2021;16(3):e2000277.

43. Mercier SM, et al. Multivariate PAT solutions for biopharmaceutical cultivation: current progress and limitations. Trends Biotechnol. 2014;32(6):329-36.

44. Marinho PA, Chailangkarn T, Muotri AR. Systematic optimization of human pluripotent stem cells media using Design of Experiments. Sci Rep. 2015;5:9834.

45. Lam J, et al. Hydrogel design of experiments methodology to optimize hydrogel for iPSC-NPC culture. Adv Healthc Mater. 2015;4(4):534-9.
46. Kuterbekov M, et al. Design of experiments to assess the effect of culture parameters on the osteogenic differentiation of human adipose stromal cells. Stem Cell Res Ther. 2019;10(1):256.

47. Matsa E, et al. Transcriptome profiling of patient-specific human iPSC-cardiomyocytes predicts individual drug safety and efficacy responses in vitro. Cell Stem Cell. 2016;19(3):311-25.

48. Glass NR, et al. Multivariate patterning of human pluripotent cells under perfusion reveals critical roles of induced paracrine factors in kidney organoid development. Sci Adv. 2020;6(2):eaaw2746.

49. Yasui R, et al. Robust parameter design of human induced pluripotent stem cell differentiation protocols defines lineagespecific induction of anterior-posterior gut tube endodermal cells. Stem Cells. 2021;39(4):429-42.

50. Shorthose S. Guide to EU pharmaceutical regulatory law. New York: Kluwer Law Intl; 2017. p. 766.

51. Rodrigues CAV, Nogueira DES, Mcabral J. Next-generation stem cell expansion technologies. Cell Gene Therapy Insights. 2018;4(8):791-804.

52. Kropp C, Massai D, Zweigerdt R. Progress and challenges in large-scale expansion of human pluripotent stem cells. Process Biochem. 2017;59:244-54.

53. EMA. Guideline on manufacture of the finished dosage form. Online document, 2017. https://www.ema.europa.eu/en/docum ents/scientific-guideline/guideline-manufacture-finished-dosage-form-revision-1_en.pdf.

54. EMA. Specifications and control tests on the finished product. Online document, 1992. https://www.ema.europa.eu/en/docum ents/scientific-guideline/specifications-control-tests-finishedproduct_en.pdf.

55. Pandey PR, et al. End-to-end platform for human pluripotent stem cell manufacturing. Int J Mol Sci. 2019;21(1):89.

56. Fluri DA, et al. Derivation, expansion and differentiation of induced pluripotent stem cells in continuous suspension cultures. Nat Methods. 2012;9(5):509-16.

57. Shafa $M$, et al. Expansion and long-term maintenance of induced pluripotent stem cells in stirred suspension bioreactors. J Tissue Eng Regen Med. 2012;6(6):462-72.

58. Wang Y, et al. Scalable expansion of human induced pluripotent stem cells in the defined xeno-free E8 medium under adherent and suspension culture conditions. Stem Cell Res. 2013;11(3):1103-16.

59. Correia $\mathrm{C}$, et al. Combining hypoxia and bioreactor hydrodynamics boosts induced pluripotent stem cell differentiation towards cardiomyocytes. Stem Cell Rev Rep. 2014;10(6):786-801.

60. Barilani $\mathrm{M}$, et al. A circular RNA map for human induced pluripotent stem cells of foetal origin. EBioMedicine. 2020;57:102848.

61. Viganò M, et al. Tips and tricks for validation of quality control analytical methods in good manufacturing practice mesenchymal stromal cell production. Stem Cells Int. 2018;2018:3038565.

62. Viganò M, Giordano R, Lazzari L. Challenges of running a GMP facility for regenerative medicine in a public hospital. Regen Med. 2017;12(7):803-13.

63. Montemurro T, et al. How we make cell therapy in Italy. Drug Des Devel Ther. 2015;9:4825-34.

64. Giordano R, et al. Clinical-grade cell purification from thawed cord blood: an example of translational research. Bone Marrow Transplant. 2003;32(9):965-6.

65. Xu P, et al. Characterization of TAP Ambr 250 disposable bioreactors, as a reliable scale-down model for biologics process development. Biotechnol Prog. 2017;33(2):478-89.

66. Cierpka K, et al. hMSC production in disposable bioreactors with regards to GMP and PAT. Chem Ing Tec. 2013;85(1-2):67-75. 
67. Nogueira DES, Cabral JMS, Rodrigues CAV. Single-use bioreactors for human pluripotent and adult stem cells: towards regenerative medicine applications. Bioengineering (Basel). 2021;8(5):68.

68. Rodríguez-Pizà I, et al. Reprogramming of human fibroblasts to induced pluripotent stem cells under xeno-free conditions. Stem Cells. 2010;28(1):36-44.

69. Liu G, et al. Advances in pluripotent stem cells: history, mechanisms, technologies, and applications. Stem Cell Rev Rep. 2020;16(1):3-32.

70. Fan Y, et al. Facile engineering of xeno-free microcarriers for the scalable cultivation of human pluripotent stem cells in stirred suspension. Tissue Eng Part A. 2014;20(3-4):588-99.

71. Serra M, et al. Process engineering of human pluripotent stem cells for clinical application. Trends Biotechnol. 2012;30(6):350-9.

72. Blakeley P, et al. Defining the three cell lineages of the human blastocyst by single-cell RNA-seq. Development. 2015;142(18):3151-65.

73. Gerecht-Nir S, Cohen S, Itskovitz-Eldor J. Bioreactor cultivation enhances the efficiency of human embryoid body (hEB) formation and differentiation. Biotechnol Bioeng. 2004;86(5):493-502.

74. Kempf H, et al. Controlling expansion and cardiomyogenic differentiation of human pluripotent stem cells in scalable suspension culture. Stem Cell Rep. 2014;3(6):1132-46.

75. Manstein F, et al. High density bioprocessing of human pluripotent stem cells by metabolic control and in silico modeling. Stem Cells Transl Med. 2021;10(7):1063-80.

76. Kinney MA, Sargent CY, McDevitt TC. The multiparametric effects of hydrodynamic environments on stem cell culture. Tissue Eng Part B Rev. 2011;17(4):249-62.

77. Wu J, et al. Oxygen transport and stem cell aggregation in stirred-suspension bioreactor cultures. PLoS ONE. 2014;9(7):e102486.

78. Sart S, et al. Crosslinking of extracellular matrix scaffolds derived from pluripotent stem cell aggregates modulates neural differentiation. Acta Biomater. 2016;30:222-32.

79. Le MNT, Hasegawa K. Expansion culture of human pluripotent stem cells and production of cardiomyocytes. Bioengineering (Basel, Switzerland). 2019;6(2):48.

80. Rodrigues AL, et al. Dissolvable microcarriers allow scalable expansion and harvesting of human induced pluripotent stem cells under xeno-free conditions. Biotechnol J. 2019;14(4):e1800461.

81. Gagliano O, et al. Microfluidic reprogramming to pluripotency of human somatic cells. Nat Protoc. 2019;14(3):722-37.

82. Haupt $\mathrm{S}$, et al. Automated selection and harvesting of pluripotent stem cell colonies. Biotechnol Appl Biochem. 2012;59(2):77-87.

83. Meng G, et al. Optimizing human induced pluripotent stem cell expansion in stirred-suspension culture. Stem Cells Dev. 2017;26(24):1804-17.

84. Xing Z, et al. Scale-up analysis for a $\mathrm{CHO}$ cell culture process in large-scale bioreactors. Biotechnol Bioeng. 2009;103(4):733-46.

85. Gupta $\mathrm{P}$, et al. Optimization of agitation speed in spinner flask for microcarrier structural integrity and expansion of induced pluripotent stem cells. Cytotechnology. 2016;68(1):45-59.

86. Kehoe DE, et al. Scalable stirred-suspension bioreactor culture of human pluripotent stem cells. Tissue Eng Part A. 2010;16(2):405-21.

87. Abbasalizadeh S, et al. Bioprocess development for mass production of size-controlled human pluripotent stem cell aggregates in stirred suspension bioreactor. Tissue Eng Part C Methods. 2012;18(11):831-51.

88. Adamo L, et al. Biomechanical forces promote embryonic haematopoiesis. Nature. 2009;459(7250):1131-5.
89. Yamamoto K, et al. Fluid shear stress induces differentiation of Flk-1-positive embryonic stem cells into vascular endothelial cells in vitro. Am J Physiol Heart Circ Physiol. 2005;288(4):H1915-24.

90. YekrangSafakar A, et al. Hollow microcarriers for large-scale expansion of anchorage-dependent cells in a stirred bioreactor. Biotechnol Bioeng. 2018;115(7):1717-28.

91. Pattasseril J, et al. Downstream technology landscape for large-scale therapeutic cell processing. BioProcess Int. 2013;11(3):38-47.

92. de Almeida Fuzeta M, et al. Addressing the manufacturing challenges of cell-based therapies. Adv Biochem Eng Biotechnol. 2020;171:225-78.

93. Fischer B, et al. A complete workflow for the differentiation and the dissociation of hiPSC-derived cardiospheres. Stem Cell Res. 2018;32:65-72.

94. Maldonado M, et al. ROCK inhibitor primes human induced pluripotent stem cells to selectively differentiate towards mesendodermal lineage via epithelial-mesenchymal transition-like modulation. Stem Cell Res. 2016;17(2):222-7.

95. Terao Y, et al. An effective detachment system for human induced pluripotent stem cells cultured on multilayered cultivation substrates using resonance vibrations. Sci Rep. 2019;9(1):15655.

96. Hassan S, et al. Allogeneic cell therapy bioprocess economics and optimization: downstream processing decisions. Regen Med. 2015;10(5):591-609.

97. Nordin M, Laurell T. Two-hundredfold volume concentration of dilute cell and particle suspensions using chip integrated multistage acoustophoresis. Lab Chip. 2012;12(22):4610-6.

98. Dawson JI, et al. Enhancing the osteogenic efficacy of human bone marrow aspirate: concentrating osteoprogenitors using wave-assisted filtration. Cytotherapy. 2013;15(2):242-52.

99. Woods EJ, et al. Off the shelf cellular therapeutics: factors to consider during cryopreservation and storage of human cells for clinical use. Cytotherapy. 2016;18(6):697-711.

100. Dakhore S, Nayer B, Hasegawa K. Human pluripotent stem cell culture: current status, challenges, and advancement. Stem Cells Int. 2018;2018:7396905.

101. Ludwig TE, et al. Feeder-independent culture of human embryonic stem cells. Nat Methods. 2006;3(8):637-46.

102. Ludwig TE, et al. Derivation of human embryonic stem cells in defined conditions. Nat Biotechnol. 2006;24(2):185-7.

103. Chen G, et al. Chemically defined conditions for human iPSC derivation and culture. Nat Methods. 2011;8(5):424-9.

104. Wang Y, Cheng L, Gerecht S. Efficient and scalable expansion of human pluripotent stem cells under clinically compliant settings: a view in 2013. Ann Biomed Eng. 2014;42(7):1357-72.

105. Lipsitz YY, Tonge PD, Zandstra PW. Chemically controlled aggregation of pluripotent stem cells. Biotechnol Bioeng. 2018;115(8):2061-6.

106. Chen AK, et al. Critical microcarrier properties affecting the expansion of undifferentiated human embryonic stem cells. Stem Cell Res. 2011;7(2):97-111.

107. Bardy JA, et al. Microcarrier suspension cultures for high-density expansion and differentiation of human pluripotent stem cells to neural progenitor cells. Tissue Eng Part C Methods. 2013;19(2):166-80.

108. Ting S, et al. An intermittent rocking platform for integrated expansion and differentiation of human pluripotent stem cells to cardiomyocytes in suspended microcarrier cultures. Stem Cell Res. 2014;13(2):202-13.

109. Badenes SM, et al. Scalable expansion of human-induced pluripotent stem cells in xeno-free microcarriers. In: Turksen $\mathrm{K}$, editor., et al., Stem cells and good manufacturing practices: 
methods, protocols, and regulations. New York: Springer; 2015. p. 23-9.

110. Badenes SM, et al. Long-term expansion of human induced pluripotent stem cells in a microcarrier-based dynamic system. J Chem Technol Biotechnol. 2017;92(3):492-503.

111. Esmonde-White KA, et al. Raman spectroscopy as a process analytical technology for pharmaceutical manufacturing and bioprocessing. Anal Bioanal Chem. 2017;409(3):637-49.

112. Doss MX, Sachinidis A. Current challenges of iPSC-based disease modeling and therapeutic implications. Cells. 2019;8(5):403.

113. $\mathrm{Xu} \mathrm{H}$, et al. Targeted disruption of HLA genes via CRISPR-Cas9 generates iPSCs with enhanced immune compatibility. Cell Stem Cell. 2019;24(4):566-578.e7.

114. Jang Y, et al. Development of immunocompatible pluripotent stem cells via CRISPR-based human leukocyte antigen engineering. Exp Mol Med. 2019;51(1):1-11.

115. Witwer KW, Théry C. Extracellular vesicles or exosomes? On primacy, precision, and popularity influencing a choice of nomenclature. J Extracell Vesicles. 2019;8(1):1648167.

116. Nguyen VVT, et al. Functional assays to assess the therapeutic potential of extracellular vesicles. J Extracell Vesicles. 2020;10(1):e12033.

117. Ragni E, et al. Extracellular vesicle-shuttled mRNA in mesenchymal stem cell communication. Stem Cells. 2017;35(4):1093-105.

118. Whitford W, Guterstam P. Exosome manufacturing status. Future Med Chem. 2019;11(10):1225-36.

119. Watson DC, et al. Scalable, cGMP-compatible purification of extracellular vesicles carrying bioactive human heterodimeric IL-15/lactadherin complexes. J Extracell Vesicles. 2018;7(1):1442088.

120. Watson DC, et al. Efficient production and enhanced tumor delivery of engineered extracellular vesicles. Biomaterials. 2016;105:195-205.

121. Barilani M, et al. NG2 as an identity and quality marker of mesenchymal stem cell extracellular vesicles. Cells. 2019;8(12):1524.

122. Zweigerdt R, et al. Scalable expansion of human pluripotent stem cells in suspension culture. Nat Protoc. 2011;6(5):689-700.

123. Olmer R, et al. Scalable expansion of human pluripotent stem cells in eppendorf BioBLUß 0.3 single-use bioreactors. Eppendorf Appl Note. 2013;292:1-4.
124. Elanzew A, et al. A reproducible and versatile system for the dynamic expansion of human pluripotent stem cells in suspension. Biotechnol J. 2015;10(10):1589-99.

125. Haraguchi Y, et al. Simple suspension culture system of human iPS cells maintaining their pluripotency for cardiac cell sheet engineering. J Tissue Eng Regen Med. 2015;9(12):1363-75.

126. Badenes SM, et al. Defined essential $8^{\mathrm{TM}}$ medium and vitronectin efficiently support scalable xeno-free expansion of human induced pluripotent stem cells in stirred microcarrier culture systems. PLoS ONE. 2016;11(3):e0151264.

127. Appelt-Menzel A, et al. Evaluation of various bioreactor process systems for the production of induced pluripotent stem cells. J Transl Sci. 2016;2:277-85.

128. Nampe D, et al. Impact of fluidic agitation on human pluripotent stem cells in stirred suspension culture. Biotechnol Bioeng. 2017;114(9):2109-20.

129. Greuel S, et al. Effect of inoculum density on human-induced pluripotent stem cell expansion in 3D bioreactors. Cell Prolif. 2019;52(4):e12604.

130. Borys BS, et al. Optimized serial expansion of human induced pluripotent stem cells using low-density inoculation to generate clinically relevant quantities in vertical-wheel bioreactors. Stem Cells Transl Med. 2020;9(9):1036-52.

131. Huang S, et al. Process development and scale-up of pluripotent stem cell manufacturing. Cell Gene Therapy Insights. 2020;6(9):1277-98.

132. Borys BS, et al. Overcoming bioprocess bottlenecks in the large-scale expansion of high-quality hiPSC aggregates in vertical-wheel stirred suspension bioreactors. Stem Cell Res Ther. 2021;12(1):55.

133. Sullivan S, et al. Quality control guidelines for clinical-grade human induced pluripotent stem cell lines. Regen Med. 2018;13(7):859-66.

134. Koenig L, et al. Production of human induced pluripotent stem cell-derived cortical neurospheres in the DASbox ${ }^{\circledR}$ mini bioreactor system. Appl Note. 2018;364:1-12.

135. Chen VC, et al. Development of a scalable suspension culture for cardiac differentiation from human pluripotent stem cells. Stem Cell Res. 2015;15(2):365-75. 